\title{
Evolution Characteristics and Relationship of Meteorological and Hydrological Droughts from 1961 to 2018 in Hanjiang River Basin, China
}

\section{Lin Wang}

Nanjing Hydraulic Research Institute

Jianyun Zhang

Nanjing Hydraulic Research Institute

Amgad Elmahdi

International Water Management Institute

Zhangkang Shu

Nanjing Hydraulic Research Institute

\section{Zhenxin Bao}

Nanjing Hydraulic Research Institute

\section{Tao Peng}

China Three Gorges University

Qingxia Lin

China Three Gorges University

Guoqing Wang (D GQWANG@NHRI.CN)

Nanjing Hydraulic Research Institute

\section{Research Article}

Keywords: Meteorological drought, Hydrological drought, Temporal and spatial evolution characteristics, Multiple scales, Response characteristics, Hanjiang River Basin

Posted Date: September 14th, 2021

DOl: https://doi.org/10.21203/rs.3.rs-450218/v1

License: (c) (i) This work is licensed under a Creative Commons Attribution 4.0 International License. Read Full License

Version of Record: A version of this preprint was published at Journal of Water and Climate Change on August 6th, 2021. See the published version at https://doi.org/10.2166/wcc.2021.267. 


\section{Evolution characteristics and relationship of meteorological and hydrological droughts from 1961 to 2018 in Hanjiang River Basin, China}

Lin Wang ${ }^{1,2}$, Jianyun Zhang ${ }^{1,2,3}$, Amgad Elmahdi ${ }^{4}$, Zhangkang Shu ${ }^{1,2}$, Zhenxin Bao ${ }^{1,2,3}$, Tao Peng ${ }^{5}$, Qingxia Lin ${ }^{5}$, Guoqing Wang ${ }^{1,2,3 *}$

1. State Key Laboratory of Hydrology-Water Resources and Hydraulic Engineering, Nanjing Hydraulic Research Institute, Nanjing, 210029, China;

2. Research Center for Climate Change, Nanjing, 210029, China;

3. Yangtze Institute for Conservation and Development, Nanjing 210098, China;

4. Head of MENA Region, International Water Management Institute, IWMI, Australia

5. China Three Georges University, Yichang, 443002, China

\section{Lin Wang}

1. State Key Laboratory of Hydrology-Water Resources and Hydraulic Engineering, Nanjing Hydraulic Research Institute, Nanjing, 210029, China;

2. Research Center for Climate Change, Nanjing, 210029, China;

E-mail:wanglin068@foxmail.com

Jianyun Zhang

1. State Key Laboratory of Hydrology-Water Resources and Hydraulic Engineering, Nanjing Hydraulic Research Institute, Nanjing, 210029, China;

2. Yangtze Institute for Conservation and Development, Nanjing 210098, China;

3. Research Center for Climate Change, Nanjing, 210029, China;

E-mail: jyzhang@nhri.cn

Amgad Elmahdi

4. Head of MENA Region, International Water Management Institute, IWMI, Australia

Email: A.Elmahdi@cgiar.org

\section{Zhangkang Shu}

1. State Key Laboratory of Hydrology-Water Resources and Hydraulic Engineering, Nanjing Hydraulic Research Institute, Nanjing, 210029, China;

2. Research Center for Climate Change, Nanjing, 210029, China;

E-mail: 513162155@qq.com

\section{Zhenxin Bao}

1. State Key Laboratory of Hydrology-Water Resources and Hydraulic Engineering, Nanjing Hydraulic Research Institute, Nanjing, 210029, China;

2. Yangtze Institute for Conservation and Development, Nanjing 210098, China;

3. Research Center for Climate Change, Nanjing, 210029, China;

E-mail: zxbao@nhri.cn

Tao Peng

5. China Three Georges University, Yichang, 443002, China

E-mail: pengtao306@163.com

Qingxia Lin

5. China Three Georges University, Yichang, 443002, China

E-mail: lqxhhu@foxmail.com

\section{Guoqing Wang*}


1. State Key Laboratory of Hydrology-Water Resources and Hydraulic Engineering, Nanjing Hydraulic Research Institute, Nanjing, 210029, China;

2. Yangtze Institute for Conservation and Development, Nanjing 210098, China;

3. Research Center for Climate Change, Nanjing, 210029, China;

E-mail: gqwang@nhri.cn

Corresponding author: Guoqing Wang

E-mail: gqwang@nhri.cn 


\section{Evolution characteristics and relationship of meteorological and hydrological droughts from 1961 to 2018 in Hanjiang River Basin, China}

Abstract: In the context of global warming and increasing human activities, the acceleration of the water cycle will increase the risk of basin drought. In this study, to analyze the spatial and temporal evolution characteristics of hydrological and meteorological droughts over the Hanjiang River Basin (HRB); the Standardized Precipitation Index (SPI) and Standardized Runoff Index (SRI) were selected and applied for the period 1961-2018. In addition, the cross-wavelet method was used to discuss the relationship between hydrological drought and meteorological droughts. The results and analysis indicated that: (1) the meteorological drought in the HRB showed a complex cyclical change trend of flood-drought-flood from 1961 to 2018. The basin drought began to intensify from 1990s and eased in 2010s. The characteristics of drought evolution in various regions are different based on scale. (2) During the past 58 years, the hydrological drought in the HRB has shown a significant trend of intensification, particularly in autumn season. Also, the hydrological droughts had occurred frequently since the 1990s, and there were also regional differences in the evolution characteristics of drought in various regions. (3) Reservoir operation reduces the frequency of extreme hydrological drought events. The effect of reducing the duration and intensity of hydrological drought events by releasing water from the reservoir is most obvious at Huangjiagang Station, which is the nearest to Danjiangkou Reservoir. (4) The hydrological drought and meteorological drought in the HRB have the strongest correlation on the yearly scale. After 1990, severe human activities and climate change are not only reduced the correlation between hydrological drought and meteorological drought in the middle and lower reaches of the basin, but also reduced the lag time between them. Among them, the hydrological drought in the upper reaches of the basin lags behind the meteorological drought by 1 month, and the hydrological drought in the middle and lower reaches of the basin has changed from 2 months before 1990 to 1 month lagging after 1990.

Keywords: Meteorological drought; Hydrological drought; Temporal and spatial evolution characteristics; Multiple scales; Response characteristics; Hanjiang River Basin

\section{Introduction}

Drought is a globally and common natural disaster, which has a huge impact on human activities and life. In recent years, it has occurred more frequently and causing more serious harm to humans in the context of global climate change and the increasing impact of human activities(Dai et al. 2018; Wyckoff and Bowers 2010). In 2014, the fifth assessment report of the IPCC pointed out that the global impact of drought will be further expanded and extended (Allen et al. 2007). Therefore, drought research has further become a hot issue of concern to scholars worldwide. As the American Meteorological Society has integrated various definitions of drought and divided drought into four types: meteorological drought, hydrological drought, agricultural drought, and socioeconomic drought. (Mishra and Singh 2010)Among them, meteorological drought refers to the phenomenon of water deficit caused by the imbalance of precipitation and evaporation in a certain period of time. It is characterized by insufficient precipitation, and the absolute precipitation of a specific duration is used as a quantitative indicator to determine the degree of drought. Hydrological drought refers to water shortages in which river runoff, reservoirs or groundwater. It affects the three major links of evaporation, infiltration and runoff in the natural water cycle process, involving the surface, soil and groundwater interface, and related to the hydrological cycle and water balance, so it can better reflect the actual drought and the difficulty of drought resistance. 
(Heim and Richard 2002; Khan et al. 2018)Besides that, meteorological drought is the source of other types of droughts, where it is closely related to the other types of drought and this relationship is particularly evident in hydrological drought(Lorenzo-Lacruz et al. 2013). At the same time, due to the impact of human activities, such as the construction of reservoirs, water transfer projects, and changes in underlying surfaces, this relationship between meteorological and hydrological has changed and impacted. Studies have shown that human activities influenced the correlation between meteorological and hydrological droughts and weakened transmission conditions(Wanders and Wada 2015).

The drought index is an effective method for drought assessment, and understand its severity, occurrence process, characteristics and impacts including its measurements (Waseem et al. 2015). According to incomplete statistics, there are as many as 100 drought indices (Fang et al. 2018). Commonly used indicators are Precipitation Anomaly Percentage (Pa), Z index, Standardized Precipitation Index (SPI),Standardized Runoff Index(SRI),Composite drought index (CI), and Palmer Drought Severity Index (PDSI) (Mukherjee et al. 2018). The SPI and SRI are two commonly used in understanding the meteorological drought and hydrological droughts for their simplicity and easy-tocalculate forms(Li et al. 2015). Yuan et al. (Yuan et al. 2016)used 6-month standard precipitation index (SPI-6) and soil moisture percentage as indicators to verify probabilistic drought forecasts in Africa, the results show that drought forecasts based on SPI6 are usually more accurate than forecasts of the soil moisture. Wang et al. (Wang et al. 2020a) used SPEI and SSI indexes to study the evolution characteristics of hydrological drought in the Yellow River Basin and its relationship with meteorological drought, they found that there was a positive correlation between hydrological and meteorological drought, and the phase angle relationships indicated that meteorological drought occurred earlier than hydrological drought in the Yellow River Basin. In addition, Huang et al. (Huang et al. 2017) used SSI to characterize the hydrological drought in the Wei River basin, and found that propagation time from meteorological to hydrological drought exhibited significant seasonal characteristics. Wu et al. (Wu et al. 2018) applied SPI and SSI to analyze the impacts of reservoir operations on multi-scale correlations between hydrological drought and meteorological drought. The characteristics of drought events can be quantitatively understood through the the drought index. Run theory is a widely used method to identify drought characteristics, which can better reflect the onset, the duration and severity of the drought events. Wu et al. (Wu et al. 2017) used run theory for the extraction of drought characteristics, including the duration, magnitude and intensity, and exploring the relationship between hydrological and meteorological droughts under influence of large reservoirs in the southeast coastal region of China. Wang et al. (Wang et al. 2019) used the three cutting levels of run theory to determine the drought event, and establish the joint distribution of drought duration and severity.

After identifying the characteristic variables of drought events based on run theory, it is useful to use the cross-wavelet transform method to investigate the correlation between meteorological drought and hydrological drought. Lin et al. (Lin et al. 2017) adopted the cross-wavelet transform method to investigate the correlation between large-scale climate indices and drought in the Xijiang Basin, South China, the authors found that hydrological drought had the most significant response to spring ENSO. Ajayi J. Oloruntadea et al. (Oloruntade et al. 2017) applied the cross-wavelet transform method to explore the correlation between SPI and SPEI, the result indicated that there are high correlation values of between 3-month scale and 12-month scale of the two drought indices.

As an important water source for the middle route of the South-to-North Water Transfer Project, the Hanjiang River Basin is also a core area for the north Hubei water resources allocation project. Its drought and flood changes are inseparable from the water supply in the Beijing-Tianjin-Hebei region and the 
north Hubei region(Liu et al. 2015). Therefore, in-depth analysis of the spatial - temporal characteristics, correlation of meteorological drought and hydrological drought in the Hanjiang River Basin (HRB) is of great significance for the allocation of water resources in the basin, economic planning, and industrial and agricultural development. Although predecessors have done some research on the meteorological drought in the HRB, there are few studies on the hydrological drought in the basin and the relationship between the two types of drought (meteorological and hydrological). Hence, studying the correlation between meteorological and hydrological droughts is very important to the early warning and management of drought risk in the basin and the rational allocation of water resources.

For that reason, this paper is exploring the following three questions: (1) What are the temporal and spatial evolution characteristics of meteorological and hydrological droughts in the Hanjiang River Basin (2) What is the relationship between meteorological and hydrological droughts (3) What are the impacts of the human activities of reservoir storage on the hydrological drought in the Hanjiang River Basin? And how does it affect the relationship with the meteorological drought? It is expected, the research results would provide the scientific foundation for the evolution and prediction of meteorological and hydrological droughts under changing environment in the Hanjiang River Basin, but also will provide decision-making support for water resources dispatching of inter-basin water transfer projects.

\section{Study area and Data source}

\subsection{Study area}

The Hanjiang River Basin (HRB) is an important water source for the South-to-North Water Diversion Project (Fig .1). The HRB is the largest tributary of the Yangtze River, with a catchment area of 159,000 $\mathrm{km}^{2}$. It is located in the transition zone of China's north-south hydrological and climatic characteristics zones. It belongs to the East Asian subtropical monsoon climate zone, where the climate is relatively warm and humid, and the yearly average precipitation ranges from 700-1800 mm, and the runoff in HRB is unevenly distributed during the year, $75 \%$ of the water volume is concentrated in May-October, so the inter-yearly changes are very large(Qin et al. 2019). We found the main types of land use of HRB in 2013 are woodland, grassland and arable land, which respectively account for $45 \%, 30 \%$ and $20 \%$ of the total area of the basin through remote sensing interpretation. More than its three-quarters of the total length flows through the territory of Hubei Province with alluvial formation where forms an important grain production area in the country-Jianghan Plain in the central part of Hubei Province and the Yangtze River(Zhou et al. 2017).After the famous South-to-North Water Diversion Project transferred water from the Danjiangkou Reservoir in the middle reaches of the HRB, the water volume in the middle and lower reaches of it was greatly reduced, which had a significant adverse impact on the production and development, and the ecological environment of the vast areas along the HRB in central Hubei province(Li et al. 2020). 


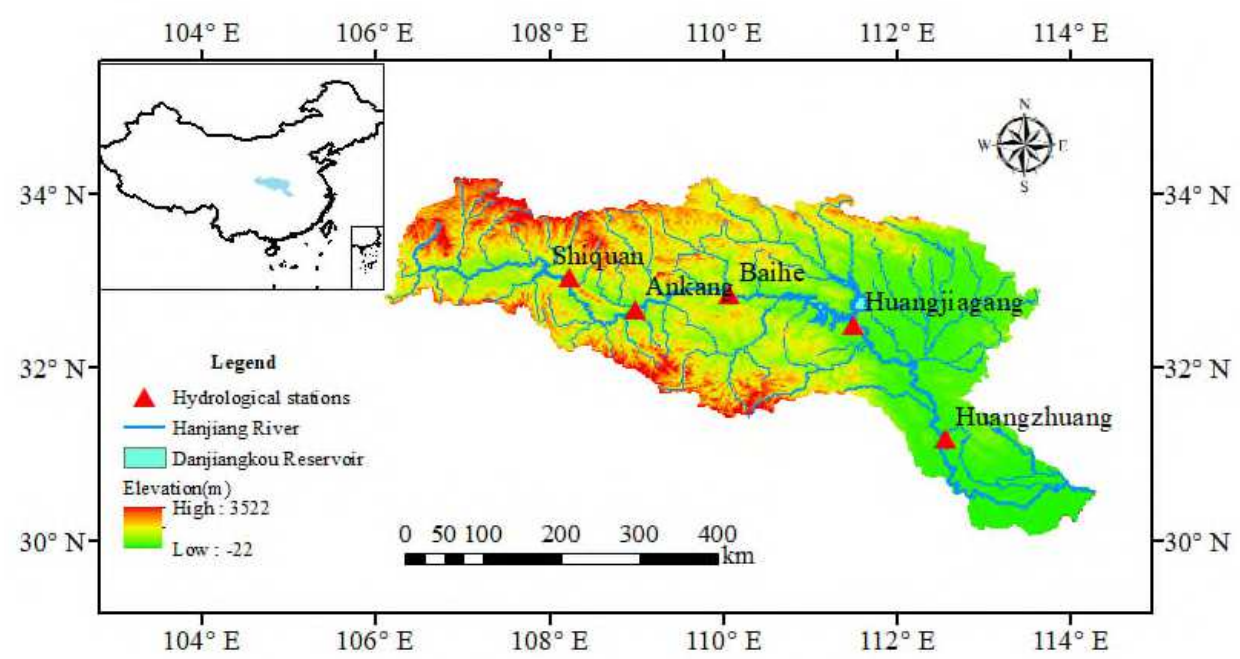

120

Fig.1 The distribution of hydrological stations in the main stream of Hanjiang River Basin

\subsection{Data source}

In this study, the meteorological data required are the daily precipitation data of 235 data grids of $0.25^{\circ} \times 0.25^{\circ}$ in the HRB for the period of 1961 to 2018 , this data accessed from the CN05.1 dataset provided by China Meteorological Administration(CMA, http://data.cma.cn), that were generated by the interpolation of more than 2400 weather stations in China through anomaly approximation method. The data is of good quality and is widely used in regional climate characteristics and model performance analysis(Diaz et al. 2020). The daily runoff data is from the five hydrological stations of Shiquan Station (SQ), Ankang Station (AK), Baihe Station (BH), Huangjiagang Station (HJG)and Huangzhuang Station (HZ) on the main stream of the HRB provided by the Hydrological Bureau of the Yangtze River Committee. It has undergone strict data inspection and quality control, which meets the needs of research. The schematic diagram of the HRB and the locations of meteorological grids, hydrological stations are shown in Fig. 1.

\section{Methodology}

First, in the studying of temporal characteristics, this paper uses the Mann-Kendall test method to analyze the mutation and trend characteristics of SPI/SRI sequences at different scales. For periodic characteristics, the authors use the Molert wavelet as the mother wavelet and combine the wavelet power spectrum method to analyze the periodicity of SPI/SRI sequences at different time scales. Then, in the research of spatial characteristics, the run theory is used to calculate the drought evaluation index. Finally, the cross-wavelet power spectrum method and the time-lag cross-correlation analysis method are used to analyze the relationship between hydrological drought and meteorological drought.

\subsection{Standardized Precipitation/Runoff Index (SPI/SRI)}

The accurate description of drought events by the drought index is the basic requirement of drought research. Yang et al. (Qing et al. 2017) evaluated the applicability of seven meteorological drought indexes in China, and the results showed that the SPI index has good applicability in humid and subhumid regions. Gümüşsoy et al. (Gümüşsoy 2017) studied the weather of the Beyşehir Lake in Turkey based on the SPI index. Drought conditions, the results show that the SPI index has a better application effect in this semiarid-humid area. The HRB flows through China's Shaanxi Province and Hubei Province. 
It belongs to a subtropical monsoon climate zone. The climate in the basin is relatively mild and belongs to a humid and semi-humid area. Considering the integrity of comprehensive data, this paper finally chose to use the SPI and SRI index to describe the meteorological and hydrological drought in the HRB.

The Standardized Precipitation Index (SPI) was used to measure the degree of meteorological drought, which is to calculate the probability of the corresponding distribution function of the precipitation in a certain period, and then carry out the normal standardization process, finally use the standardized precipitation cumulative frequency distribution to divide the drought level(Yao et al. 2018). Since the standardization process can eliminate the difference in the temporal and spatial distribution of precipitation, SPI can well reflect the drought situation in the region under different research scales(Zhao et al. 2020). The calculation formula is as follows(Caccamo et al. 2011; McKee T B 1993; Qi et al. 2018):

First, suppose that the precipitation(flow) sequence during the study period is $x$, then the probability function of this sequence is:

$$
f(x)=\frac{1}{\beta^{y} \tau(y)} x^{y-1} e^{-x / \beta}
$$

Where $x>0, \quad \beta>0, \quad \gamma>0 ; \beta$ and $\gamma$ are the scale parameter and shape parameter of the above probability distribution function, respectively. The parameter estimation method adopts the maximum likelihood method to obtain:

$$
\begin{gathered}
y=\frac{1+\sqrt{1+4 A / 3}}{4 A} \\
\beta=\bar{x} / y \\
A=\lg \bar{x}-\frac{1}{n} \sum_{i=1}^{n} \lg x_{i}
\end{gathered}
$$

Where $x_{i}$ is the period precipitation, $\bar{x}$ is the average value of the period precipitation.

After the above parameters are calculated, combined with formula (1), according to statistical principles, when the precipitation rate in a certain period of time is $x_{0}$, the probability of the time when the rate of the period precipitation $x<x_{0}$ is:

$$
F\left(x<x_{0}\right)=\int_{0}^{x_{0}} f(x) d x
$$

When the $x_{i}=0$, there are:

$$
F(x)=u+(1-u) G(x)
$$

Where $u=m / n, m$ is the number of periods when $x_{i}=0, n$ is the total length of the sequence.

Then, combining equations $(5) \sim(6)$, and substituting the solved probability values into the standardized normal distribution function respectively:

$$
F\left(x<x_{0}\right)=\frac{1}{\sqrt{2 \pi}} \int_{0}^{x} e^{-z^{2} / 2} d x
$$

At last, the calculation formula of SRI is obtained by the integration of the formula (7): 


$$
S R I=S * \frac{t-\left(c_{2} t+c_{1}\right) t+c_{0}}{\left(\left(d_{3} t+d_{2} t\right)+d_{1}\right) t+1.0}
$$

Where $t=\sqrt{\ln \left(1 / G(x)^{2}\right.}, G(x)$ is the probability of the precipitation distribution associated with the $\tau$ function. when $G(x)>0.5, G(x)=1-G(x), S=1$; or $G(x)<0.5, S=-1$. The values of other parameters is $\mathrm{c}_{0}=2.515517, \mathrm{c}_{1}=0.802853, \mathrm{c}_{2}=0.010328, d_{1}=1.432788, d_{2}=0.189269, d_{3}$ $=0.001308$ (Jiang et al. 2019). The hydrological drought is often associated with river basin runoff. The SRI was used to represent the hydrological drought in this study because its calculation steps and advantages are similar to those of the SPI, the SPI calculation formula rainfall is replaced with flow rate for calculation (Chen et al. 2018). The SPI and SRI classifications of the drought levels are listed in Table 1 and correspond to classifications used in previous studies(Hao et al. 2016).

\begin{tabular}{cc}
\multicolumn{2}{c}{ Table 1 Classification of Standardized Drought Index (SPI/SRI) } \\
\hline SPI/SRI Value & Drought Level \\
\hline$(-1.0,-0.5]$ & Light Drought \\
$(-1.5,-1.0]$ & Moderate Drought \\
$(-2.0,-1.5]$ & Severe Drought \\
$\leq-2.0$ & Extreme Drought \\
\hline
\end{tabular}

\subsection{Drought Evaluation Index}

(1) Drought Tendency

The Mann-Kendall (MK) test method is a non-parametric test method recommended by the World Meteorological Organization. It is also a commonly used method to test the evolution trend and sequence mutation of variables. It is easy to test non-normally distributed variables such as hydrological and meteorological elements and less disturbed by variable abnormal values, so it has been widely used in meteorology, hydrology and other fields (Yilmaz 2019). The M-K trend test method and the M-K mutation test method were used to test and analyze the trend and mutation of the SPI/SRI sequence respectively. The specific processes of the two calculation methods are as follows(Kendall 1990; Mann 1945):

(1)The M-K trend test

Set $x_{1}, x_{2}, \ldots, x_{n}$ as a list of time series variables, $n$ is the length of the research series, and define statistics as follows:

$$
s=\sum_{j=1}^{n-1} \sum_{k-j+1}^{n} \operatorname{sgn}\left(x_{k}-x_{j}\right)
$$

Where $x_{k}, x_{j}$ is the precipitation of the $j_{\mathrm{th}}$ and $k_{t h}$ year, $k>j$.

$$
\operatorname{sgn}\left(x_{k}-x_{j}\right)=\left\{\begin{array}{l}
1\left(x_{k}-x_{j}>0\right) \\
0\left(x_{k}-x_{j}=0\right) \\
-1\left(x_{k}-x_{j}<0\right)
\end{array}\right.
$$

Construct normal distribution statistics $Z$, The expression is as follows:

$$
Z=\left\{\begin{array}{l}
\frac{s-1}{\sqrt{\operatorname{Var}(s)}}(\mathrm{s}>0) \\
0(\mathrm{~s}=0) \\
\frac{s+1}{\sqrt{\operatorname{Var}(s)}}(\mathrm{s}<0)
\end{array}\right.
$$


At a given confidence level $\alpha$, if $|Z| \geq Z_{1-\alpha / 2}=1.96(\alpha=0.05)$, which indicates that the original

hypothesis is rejected, and the studied time series has a significant upward or downward trend at a given confidence level. The specific trend size is calculated by the following formula:

$$
\beta=\text { Median }\left|\frac{x_{k}-x_{j}}{k-j}\right|, \forall j<k
$$

If $\beta>0$, it means that the SPI/SRI sequence is on an upward trend, which means which means the drought become serious; otherwise, it means that the sequence is on a downward trend, it means the drought has a tendency to slow down.

(2)The M-K mutation test method

First, constructing an order column for a time series $\mathrm{x}$ with $\mathrm{n}$ sample sizes:

$$
\begin{aligned}
& s_{k}=\sum_{i=1}^{k} r_{i}(k=1,2, \ldots, n) \\
& r_{i}=\left\{\begin{array}{l}
1\left(x_{i}>x_{j}\right) \\
0\left(x_{i} \leq x_{j}\right)
\end{array}(j=1,2, \ldots, \mathrm{n})\right.
\end{aligned}
$$

Among them, the order column is the sum of the number at the i-th time greater than the number at the j-th time.

Then, defining statistics UF under the assumption of random independence in the time series:

$$
U F_{k}=\frac{\left[s_{k}-E\left(s_{k}\right)\right]}{\sqrt{\operatorname{Var}\left(s_{k}\right)}},(k=1,2, \ldots, n)
$$

Where $U F_{1}=0, E\left(s_{k}\right), \operatorname{Var}\left(s_{k}\right)$ are the mean and variance of the study sequence respectively, and the calculation formula is as follows:

$$
\begin{gathered}
E\left(s_{k}\right)=n(n+1) / 4 \\
\operatorname{Var}\left(s_{k}\right)=n(n-1)(2 n+5) / 72
\end{gathered}
$$

Finally, arranging the SPI/SRI sequence in reverse order, and calculating the statistic $\mathrm{UB}_{\mathrm{k}}$ according to the above formula, while satisfying:

$$
\left\{\begin{array}{l}
U B_{k}=-U F_{k} \\
k=n+1-k
\end{array}\right.
$$

According to the above formula, using the SPI sequence and SRI sequence as data input, then the $\mathrm{UF}_{\mathrm{k}}$ and $\mathrm{UB}_{\mathrm{k}}$ curves of the studied time series are calculated. If the value of UF is greater than 0 , it indicates that the sequence is on an upward trend, which means the drought become serious; and if the value is less than 0 , the sequence is on a downward trend, which means the drought has a tendency to slow down. When UF exceed the critical straight line $( \pm 1.96)$, it indicates that the drought tendency is significant. And the time point corresponding to the intersection of the the UF and UB in the critical interval is the time when the sudden drought change begins. If the intersection of the UF and UB exceeds the critical value $\alpha=0.05$, it indicates that the probability of mutation is very high on this time.

\section{(2) Drought Frequency}

This study calculates the occurrence of drought in the four seasons and years of the HRB from 1961 to 2018 , and obtains the drought frequency in the past years and quarters. The drought frequency refers 
to the percentage of regional drought occurrence time in the length of the time series (Lin et al. 2020):

$$
P=(n / m) \times 100 \%
$$

In the formula, $n$ is the actual number of drought occurrences and $m$ is the sequence length.

(3) Drought Intensity

The drought intensity can be expressed by the absolute value of SPI/SRI during the period of a certain drought event. The smaller the drought intensity, the less obvious drought conditions here (Chiang et al. 2018). The calculation formula is:

$$
S_{i, j}=\frac{1}{m} \sum_{i=1}^{m}\left|S P I_{i}\right|
$$

where: $i$ is the codes of different stations; $j$ is the year; $m$ is the total number of stations where drought events occur.

(4) Drought Duration

Similarly, using run theory to identify drought events in the time series, the length of the negative run of a drought event is the drought duration(Montaseri et al. 2018).

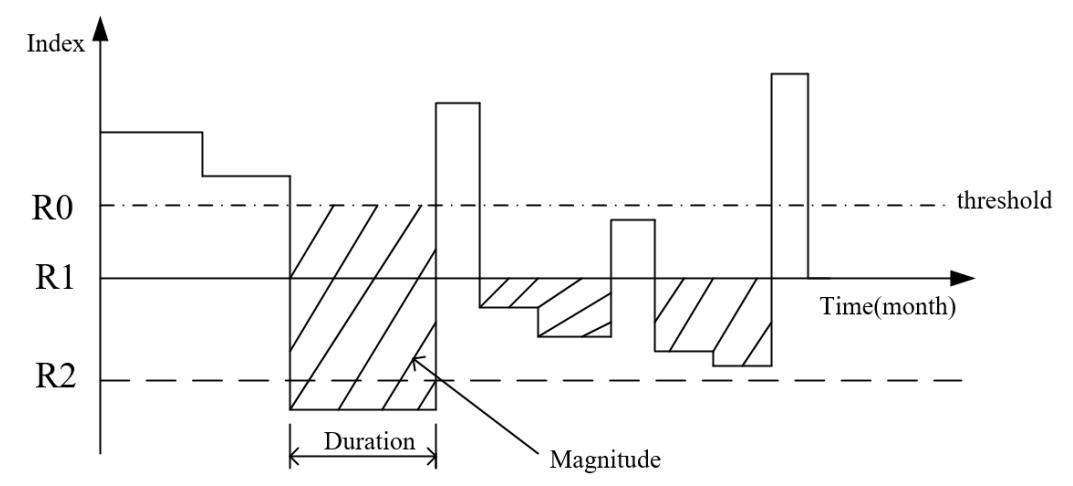

Fig. 2 The drought characteristics of run theory, including drought duration, drought intensity and drought magnitude

\subsection{Time-Delay Cross-Correlation Analysis}

The time-lag cross-correlation analysis is a method of moving a certain time series backward for a period of time and then performing correlation analysis with another time series(Sattar et al. 2019). The time lag of the interaction between elements of different time series is considered, so this method is suitable for studying the lag time of hydrological drought to meteorological drought(Xu et al. 2019).

Assuming that the 2 time series $x$ and $y$ have correlation with any lag time $k$, then the time lag correlation coefficient of the studied series is expressed as:

$$
r_{k}=\frac{C_{k}(x, y+k)}{\sigma_{x} \sigma_{y+k}}
$$

Where $C_{k}(x, y+k)$ is the covariance of the $x$ series and the time series $y+k$ with increasing lag time $k$, and $\sigma_{x} \sigma_{y+k}$ is the mean square error of the two researched series, respectively expressed as: 


$$
\left\{\begin{array}{l}
C_{k}(x, y+k)=\frac{1}{n-1} \sum_{i=1}^{n-k}\left(\mathrm{y}_{i+k}-\overline{\mathrm{y}_{i+k}}\right)\left(x_{i}-\overline{x_{i}}\right) \\
\sigma_{x}=\left[\frac{1}{n-1} \sum_{i=1}^{k}\left(x_{i}-\overline{x_{i}}\right)^{2}\right]^{1 / 2} \\
\sigma_{y+k}=\left[\frac{1}{n-1} \sum_{i=1}^{k}\left(\mathrm{y}_{i+k}-\overline{\mathrm{y}_{i+k}}\right)^{2}\right]^{1 / 2}
\end{array}\right.
$$

\section{Results and Discussion}

\subsection{The Evolution Characteristics of Meteorological Drought}

\subsubsection{Temporal Evolution Characteristics}

Fig. 3 illustrates the SPI at different scales with different sensitivity to drought, and as the time scale increases, the sequence fluctuations gradually decrease. It shows that the SPI value of the HRB has been in a state of flood-drought-flood-drought with complicated periodic changes from 1961 to 2018, which has obvious periodic characteristics. Drought occurred more frequently in the HRB at various scales from 1962 to 1980 and 1990 to 2011. After 2011, the overall drought trend eased slightly, but the drought phenomenon still appears periodically, this trend becomes more and more significantly serious as the temporal scale increases from 1-12 months.
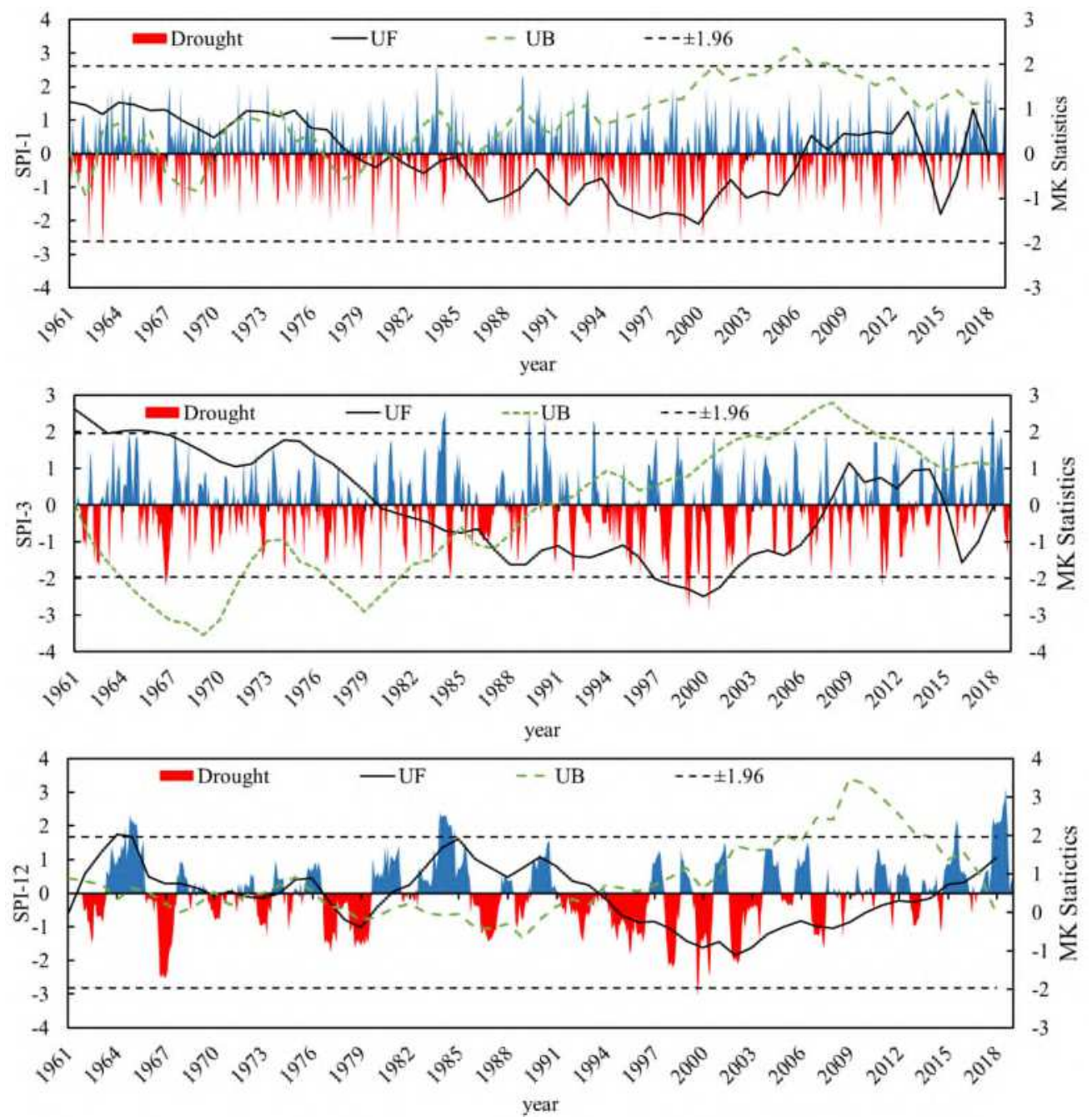

Fig. 3 The Change Process of SPI Index and MK Abrupt Curve of SPI-1, SPI-3 and SPI-12 metrological drought in HRB. The red area represents drought, the blue area is rainy. UF and UB are the order and reverse order of the SPI sequence in the M-K 

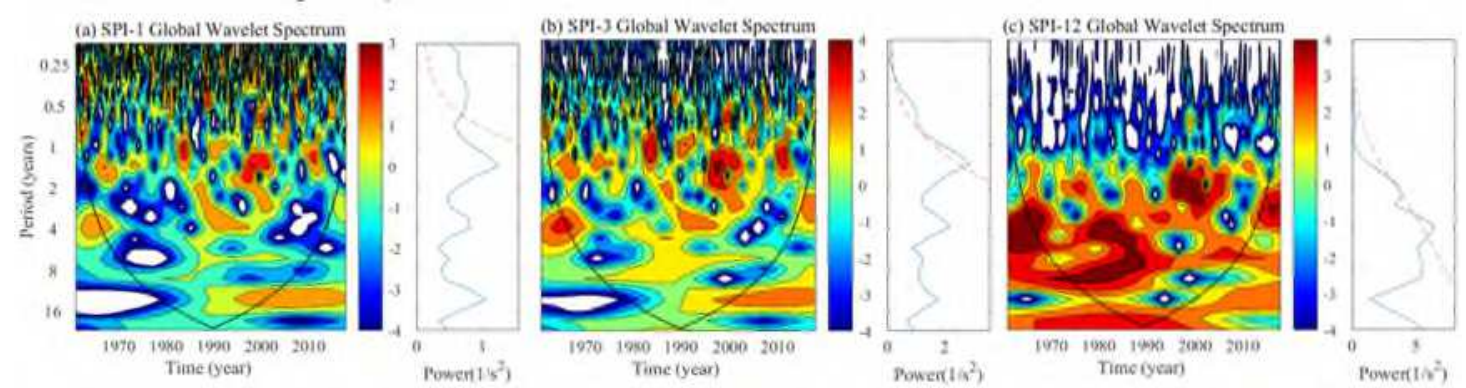

Fig. 4 The wavelet power spectrogram of SPI-1, SPI-3 and SPI-12 metrological drought in HRB. The black solid line on the left picture is the wavelet influence cone, which represents the wavelet spectrum area generated by the sequence transformation and the corresponding edge effect. The red dotted line on the right represents the significance of the wavelet area under the red noise background spectrum, and the blue solid line represents the wavelet variance. The periodicity of the left chart corresponding to the extreme value of the wavelet variance in the confidence interval represented by the red dashed line is the significant periodicity of the study sequence.

At the same time, combine with the M-K mutation curve, most of the periods are gradually changing from mild drought to aggravation and then to drought relief, which is reflected in the sudden change of the state transition before and after the point in each time scale. The mutation points are mainly concentrated in 1974, 1980,1994, but did not exceed the critical line, so the sudden change of meteorological drought in the HRB was not significant. According to Wang et al. (Wang et al. 2019a) research results, the HRB transitioned from the rainy period in the 1980s to the drier period in the 1990s, the precipitation has shown an insignificant downward trend in the past 60 years, and the SPI value is directly affected by precipitation. Therefore, the non-significant abrupt change of the scale is also more consistent with the precipitation changes in the HRB. Besides that, due to the calculation difference and time generalizability of different scales, the mutation points of varied scales are different.

The SPI-1, SPI-3, and SPI -12 changes in the HRB from 1961 to 2018 showed certain periodic characteristics (Fig. 4). It can be seen that the frequency domain scale of the energy center in the wavelet power spectrum does not pass the 0.05 significance level, so the periodicity of SPI- 1 is not obvious. On the contrary, the frequency domain scale of the energy center and the extreme value of the wavelet variance of the SPI-3 reaches the extreme value is about 2 years, and it has passed the 0.05 significance level test, so the periodicity of SPI-3 is significant. The periodicity of SPI-12 is more significant, the frequency domain scale of the energy center is mainly concentrated over 4 years, and the SPI-12 value oscillates most strongly at 4 years. Because the time scale of monthly SPI is relatively meticulous, and the sequence fluctuation noise is obvious, which leads to insignificant periodic changes. However, the seasonal and yearly scale SPI eliminates some noises relative to the monthly scale sequence, so significant periodic characteristics are identified(Niu and Chen 2016).

\subsubsection{Spatial Evolution Characteristics}

In order to facilitate the subsequent exploration of the relationship between hydrological drought and meteorological drought, the HRB is divided into four spatial areas according to the location of hydrological stations. Below Huangzhuang Station is Area I, above is Area II, and above Huangjiagang Station is Area III, and Baihe Station above is area IV. And Region I correspond to the downstream of the basin, Region II corresponds to the middle reaches of the basin, and Regions III and IV correspond to the upper reaches of the region.

The spatial characteristics of the SPI-12 meteorological drought of the HRB are shown in Fig .5. At the yearly scale, the HRB shows a clear trend of aridification in the central region but humidification in 
the southern and western regions (Fig .5a). The significant aridification areas are mainly distributed in Region II, the proportion of significant aridification grid points in the region is $50.7 \%$, the proportion of aridification grid points is $87.32 \%$ of Regions III. And the significant humidification regions are mainly distributed in regions I and IV, where the significant humidification grids in the region is $47.67 \%$ and $66.7 \%$ respectively. From the point of view of the frequency and duration of drought (Fig .5c \& Fig .5d), the frequency of drought events in Region IV is the highest at $38.01 \%$, while the drought duration is the longest at the same time, with an average drought duration of 11.26 months, and it is also with the most occurrence of light drought events. Among them, the frequency of drought in Region I is relatively low, and its duration is the shortest, but the frequency of severe drought and extreme drought events is relatively highest. Overall, although the frequency of drought in Region III is not high, its drought intensity is the highest, and the drought duration is second only to Region IV. It is necessary to prevent the impact of sudden drought events in Region III(Zhang et al. 2019).

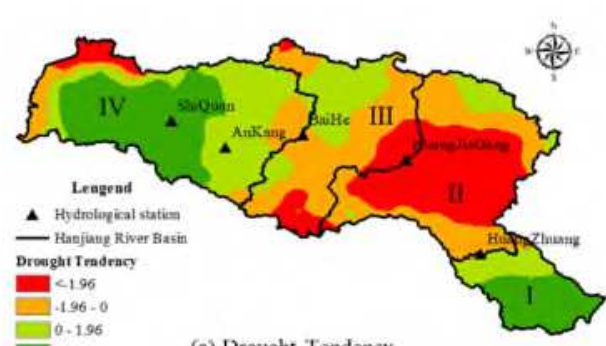

(a) Drought Tendency

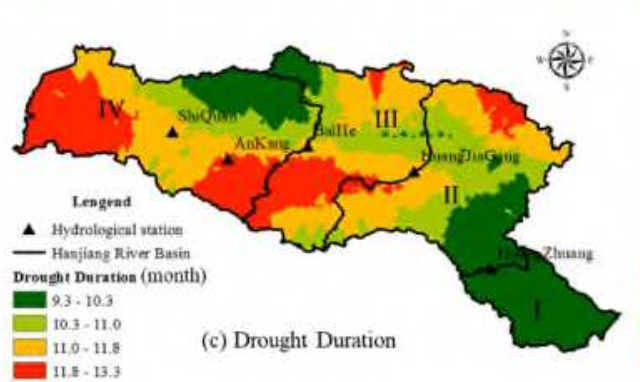

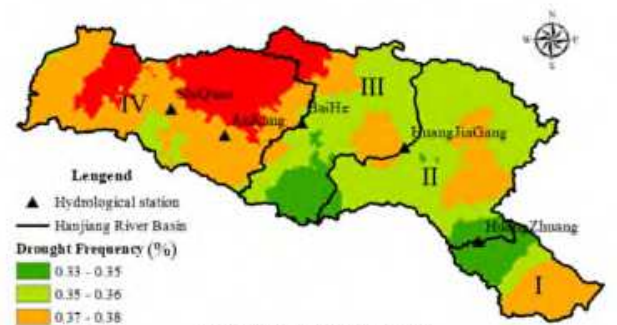

(b) Drought Frenquency

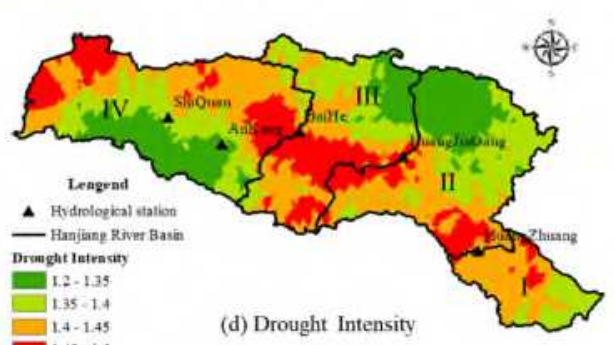

Fig. 5 The spatial distribution of drought tendency, drought frequency, drought duration and drought intensity of SPI-12 meteorological drought in HRB. The I, II, III, IV represent four regions. Below Huangzhuang Station is Area I, above is Area II, and above Huangjiagang Station is Area III, and Baihe Station above is area IV. And Region I correspond to the downstream of the basin, Region II corresponds to the middle reaches of the basin, and Regions III and IV correspond to the upper reaches of the region.

From seasonality perspective, the spatial characteristics of meteorological drought in the HRB have obvious differences and variability between the four seasons (Fig .6). In spring, the trend of aridification in areas III and IV in the upper reaches of the HRB is more obvious, but the proportion of significant aridification in the area is relatively low, only $2.87 \%$, where the frequency of drought in area III is higher, light droughts and moderate droughts are occur frequently, and the drought duration is long and drought intensity is high. In summer, the trend of aridification in Region II was more obvious, and the drought frequency was $33.58 \%$. Region I had the highest drought intensity at 1.206, and Region IV had the longest drought duration at 2.046 months. In autumn, the entire basin showed a drought trend, where Region II was the most significant, the drought in Region III was long and strong, the frequency of drought in Region IV was high, and the frequency of moderate drought events was relatively highest. In winter, the aridification trend of area IV is the most significant, and the drought intensity is the highest, area III has the highest drought frequency and the longest drought duration. Taken together, the four seasons of 
drought conditions in the upper and middle reaches of the HRB are relatively severe. The summer drought of area II in the middle reaches is more severe, and the winter drought is more serious in area IV in the lower reaches of the HRB.
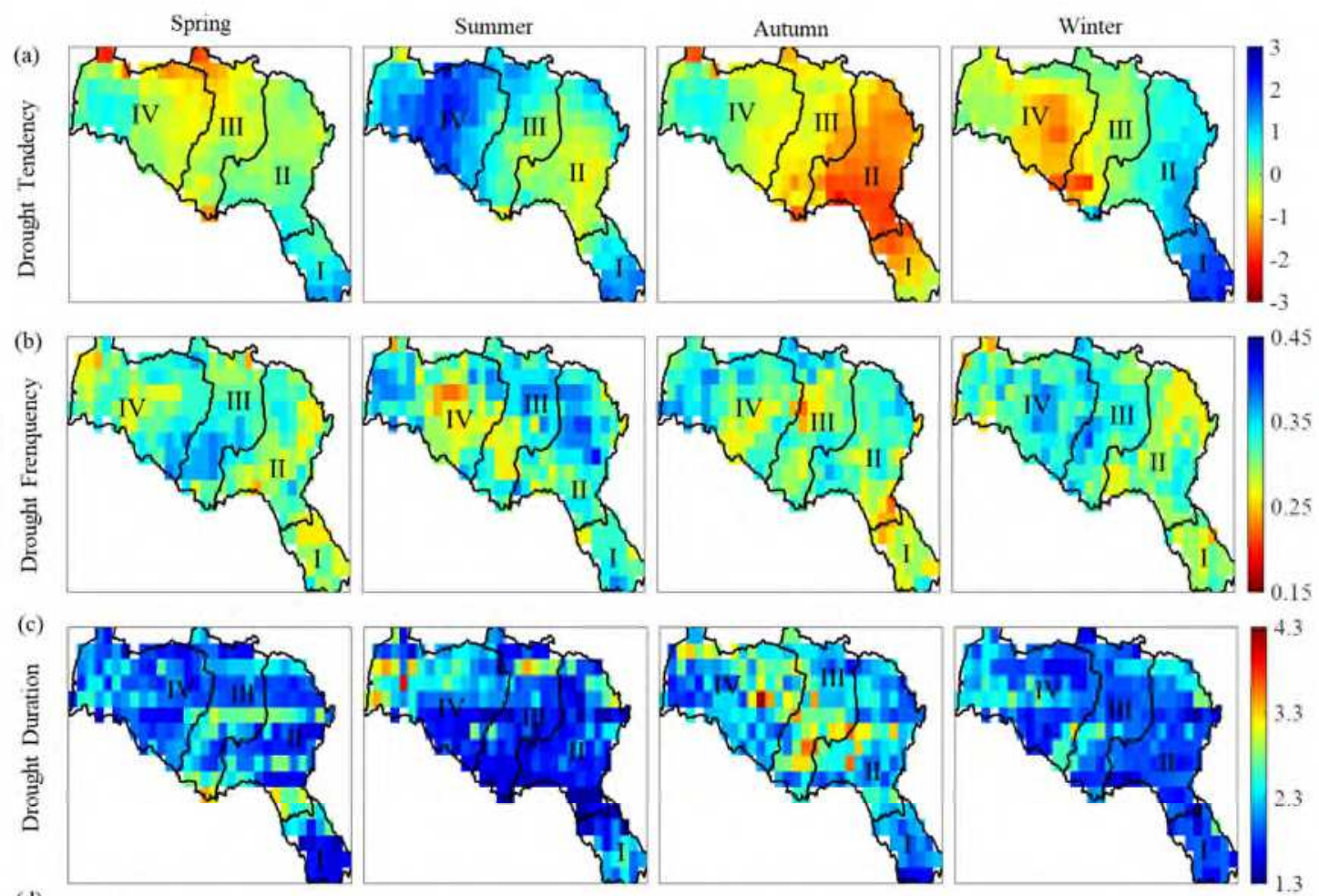

(d)
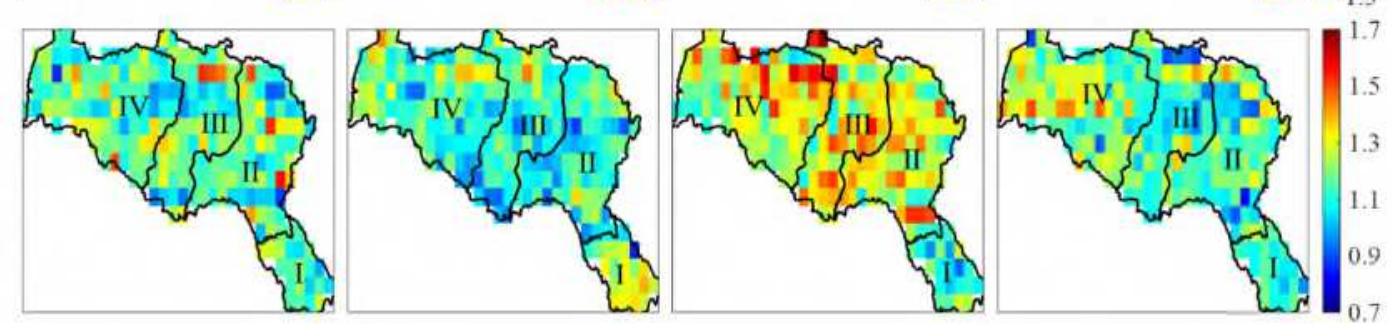

353

354

355

Fig. 6 The spatial distribution of drought tendency, drought frequency, drought duration and drought intensity at seasonal-scale meteorological drought in HRB. The I, II,III, IV represent four regions.

\subsection{The evolution characteristics of hydrological drought}

\subsubsection{Temporal Evolution Characteristics}

The M-K test method was used to understand the trend of the hydrological drought index SRI series at seasonal and yearly scales for the 5 hydrological stations within the HRB (Table 2). The yearly hydrological drought index trend recorded a significant decreasing trend, that is, the aridification trend became more obvious, and the aridification trend of the area near HJG was the most obvious. At a seasonal scale, the spring and autumn droughts aggravated in the entire river basin. The spring droughts at $\mathrm{SQ}, \mathrm{AH}$, and BH stations in the upper HRB have a significant trend. The autumn droughts in the control basins of stations other than the SQ station also showed a trend of aridification. And the increasing trend of summer drought in HJG region is more obvious, and it is prone to continuous drought in summer and autumn, while winter in the whole basin shows a trend of insignificant humidification to varying degrees. Wang et al (Wang et al. 2020c) found that the spring drought in Shaanxi Province tended to increase. and Ge's (Ge 2019; Wang et al. 2020c) study indicated that various regions of Shaanxi Province have shown 
different degrees of aridification trends in spring and autumn in recent years, and SQ, AK, and $\mathrm{BH}$ all have increased trends in spring and autumn droughts, but the increase in autumn drought at Shiquan Station is not obvious. This is consistent with the conclusion of this paper.

Table 2 The M-K trend test value of seasonal-scale and yearly-scale hydrological drought in the five htdrological stations in HRB, the test value $|Z|=1.96$, it is a significant change when the absolute value of the test value exceeds it, and it is bolded in the table

\begin{tabular}{cccccc}
\hline Station & Spring & Summer & Autumn & Winter & Yearly \\
\hline Shiquan(SQ) & $\mathbf{- 3 . 1 2}$ & -0.88 & -1.48 & 0.91 & -2.09 \\
Ankang(AK) & $\mathbf{- 2 . 4 3}$ & -0.49 & $\mathbf{- 2 . 6 2}$ & 1.09 & -1.95 \\
Baihe(BH) & $\mathbf{- 2 . 4 1}$ & -0.69 & $\mathbf{- 2 . 4 8}$ & 1.13 & -1.95 \\
Huangjiagang(HJG) & -1.84 & $\mathbf{- 1 . 9 9}$ & $\mathbf{- 3 . 4 3}$ & 0.74 & -2.25 \\
Huangzhuang(HZ) & -1.64 & -1.82 & $\mathbf{- 2 . 7 4}$ & 0.93 & -1.71 \\
\hline
\end{tabular}

Similarly, taking the HJB Station in the middle reaches of the basin as an example, the hydrological drought in the basin also has obvious temporal and periodic characteristics(Fig .7). From the perspective of SRI changes at different time scales, the hydrological drought in the HRB from 1961 to 2018 showed cyclical fluctuations of flood-drought-flood-drought. The droughts occurred at various time scales and more frequent after the 1990s, with long duration and high intensity. This phenomenon is related to the HRB from the rainy period to the drier period since the 1990s (Mu et al. 2012; Zhang et al. 2008). Among them, SPI-1, there are more low droughts, while the number of extreme droughts of SPI-3 and SPI-12 is greater than that on the monthly scale. This is because the difference in data processing during SRI and SPI calculations. The wavelet power spectrum results show that the periodicity of the monthly-scale SRI series in the HRB is not significant, and the yearly and seasonal SRI series have a main period of 8 years (Fig .8).

The mutation points observed at 1994,2002-2007,2012, and the overall drought situation shows a trend that firstly slowing down and then intensifying.Firstly, the time of all mutation points appearance not only lags behind the sudden change of meteorological drought, but also these mutuation points appeared after the construction of a large number of water conservancy projects in the HRB, which indicating that the drought in the basin is severely affected by human activities.Besides that, the authors have noticed since 2014, the meteorological drought in the HRB has been slowing down, but hydrological drought events have shown a high incidence, and the peak of hydrological drought is significantly smaller than meteorological drought, as such the meteorological and hydrological droughts show obvious inconsistency trend. This is inextricably related to the water transfer from the Danjiangkou Reservoir in the middle reaches of the HRB in the South-to-North Water Diversion Project in 2014. On one hand, human activities such as the interception of water by reservoirs and the diversion of water through the diversion projects have aggravated the hydrological drought in the Hanjiang River Basin. On the other hand, the release of water during the dry season from the reservoir has a certain mitigation effect on extreme drought events in the basin(Wu et al. 2016). 

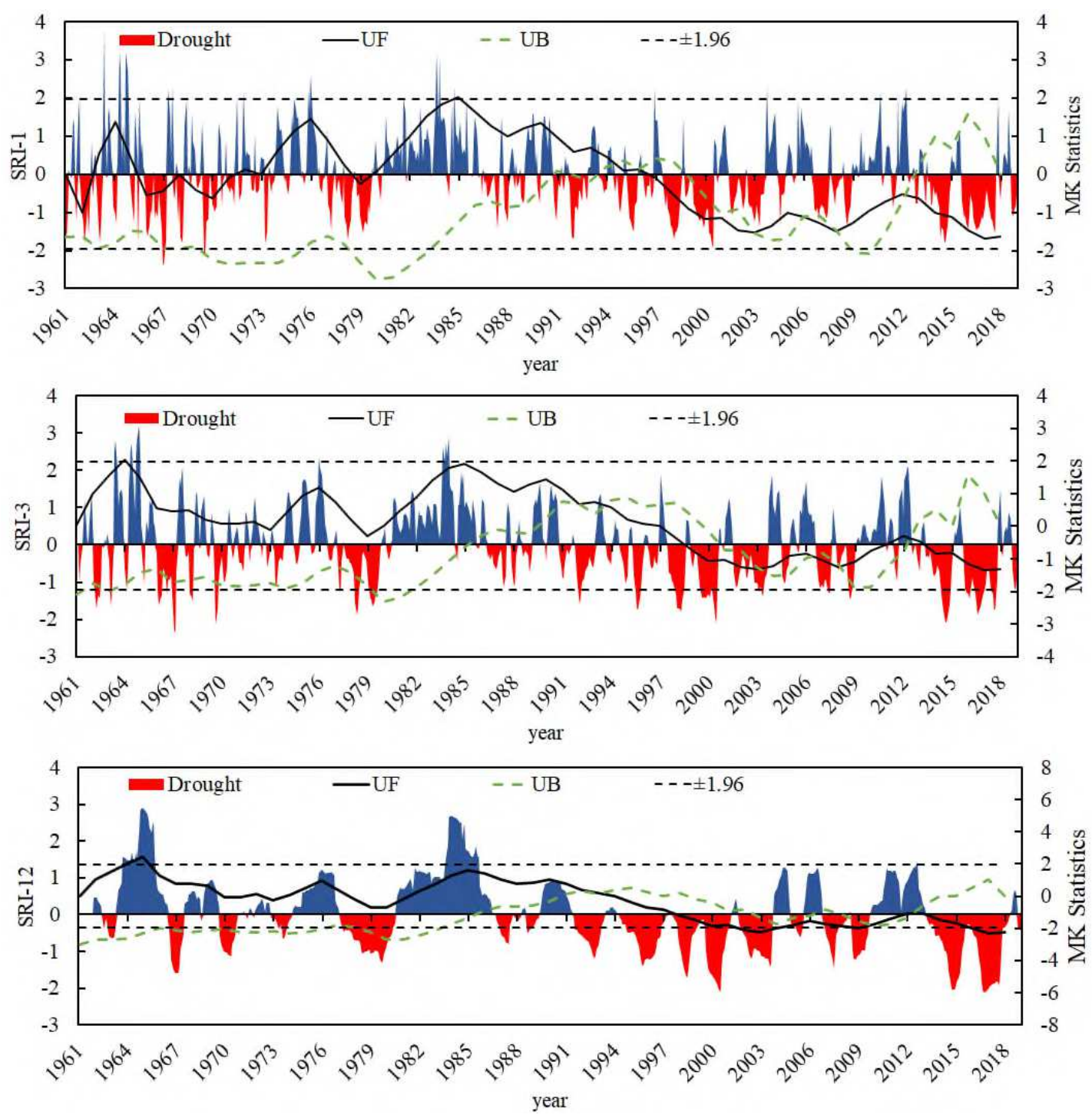

Fig.7 The Change Process of SRI Index and MK Abrupt Curve of SPI-1, SPI-3 and SPI-12 hydrological drought in Huangjiagang station. The red area represents drought, the blue area is rainy. UF and UB are the order and reverse order of the SRI sequence in the M-K mutation test method, respectively.
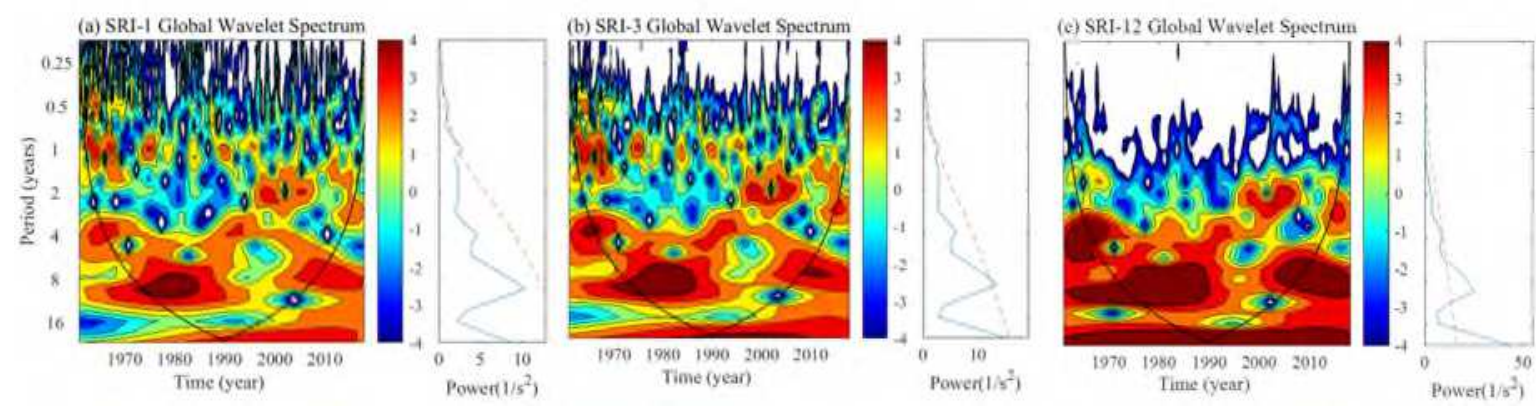

Fig. 8 The wavelet power spectrogram of SRI index of SRI-1, SRI-3 and SRI-12 hydrological drought in Huangjiagang station.

The black solid line on the left picture is the wavelet influence cone, which represents the wavelet spectrum area generated by the sequence transformation and the corresponding edge effect. The red dotted line on the right represents the significance of the wavelet area under the red noise background spectrum, and the blue solid line represents the wavelet variance. The periodicity of the left chart corresponding to the extreme value of the wavelet variance in the confidence interval represented by the red dashed line is the significant periodicity of the study sequence. 
Fig .9 shows the frequency of occurrence at the five hydrological stations on the main stream of the HRB under different scenarios from the seasonal perspectives. In spring, the Shiquan and Baihe regions have the highest frequency of drought events, while the Ankang and Huangzhuang regions recorded the highest extreme events. In summer season, the overall drought frequency in the basin is greater than spring, the Shiquan and Huangzhuang regions have the highest drought frequency, and the Huangjiagang region has the highest drought frequency for extreme drought events. However, autumn season reported the highest frequency of drought events, Shiquan, Huangjiagang, and Huangzhuang regions have the highest frequency of drought events, while the region above the Baihe River has recorded the highest frequency of extreme drought events. During winter, Shiquan region has the highest frequency of drought events, while the extreme drought occurs most frequently at the Baihe region.
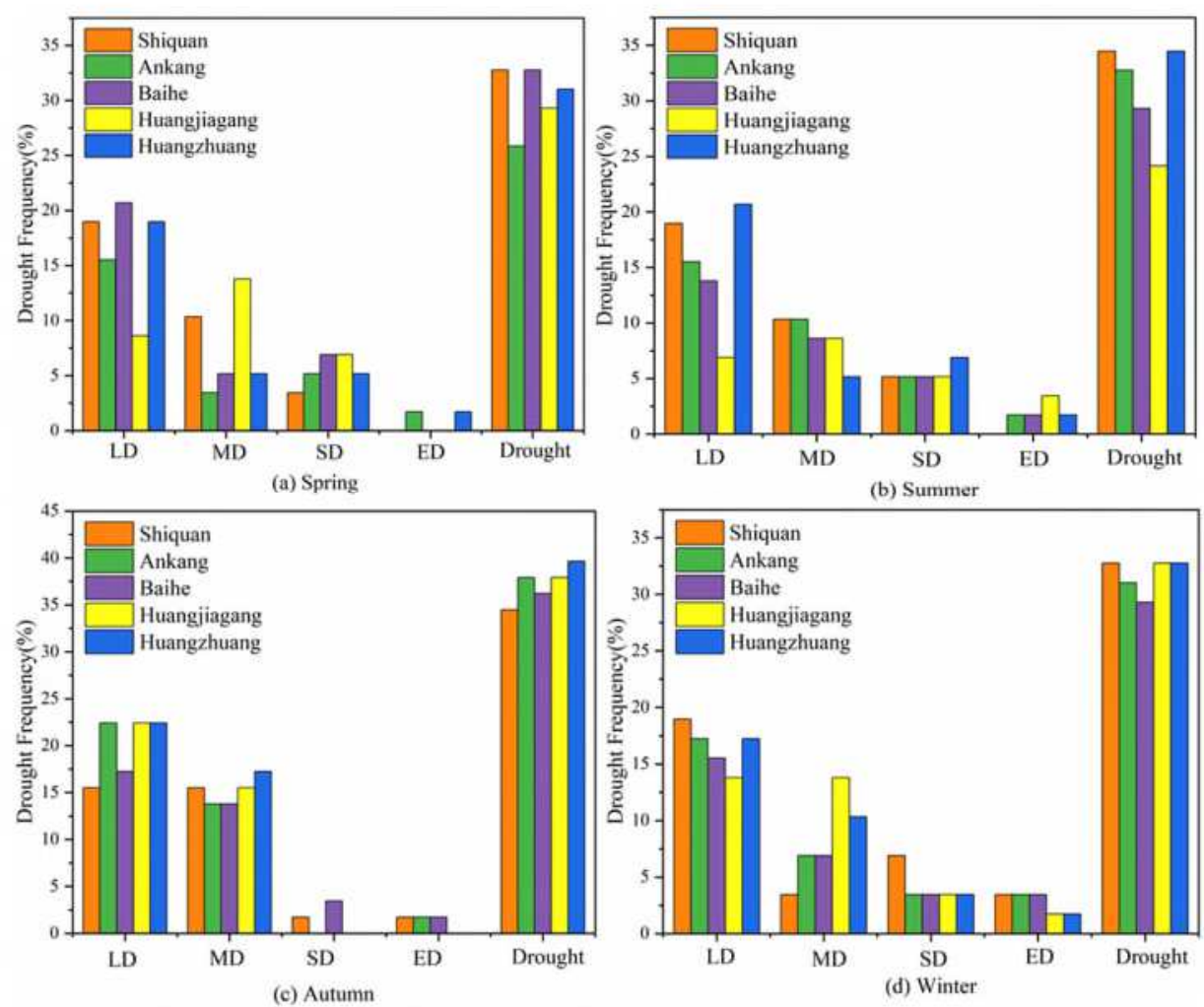

Fig. 9 Seasonal hydrological drought frequency of different types of drought events of five hydrological stations in HRB, LD is light drought events, MD is moderate drought events, SD is severe drought events, ED is extreme drought events.

From the perspective of drought duration and drought intensity (Fig .10), the Baihe Station has reported the highest drought intensity except during summer; the Shiquan Station has the longest drought duration in spring and summer, especially with the largest drought intensity recorded in summer. The Huangzhuang Station has the longest drought duration in autumn and winter but the drought intensity is not large. It is worth noting that the drought intensity of Huangjiagang Station is the lowest, and also the lowest drought intensity of the light drought in all four seasons. This could be attributed to the release of water during the dry season from the reservoir which has a certain weakening effect on its drought intensity, which lessen the seasonal drought at Huangjiagang Station to a certain extent(Zhang et al. 2015). 

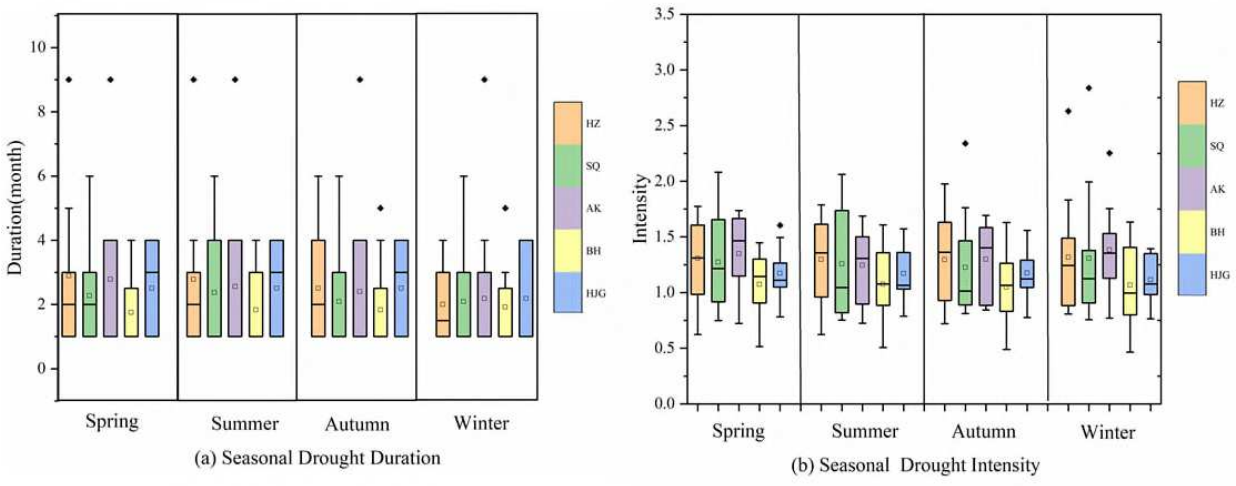

Fig. 10 The drought duration and drought intensity of five hydrological stations at the seasonal scale in HRB.

Table 3 compares the characteristics of hydrological drought events with the corresponding drought characteristics of meteorological drought events at seasonal scale. Except for summer, the frequency of meteorological droughts at other scales is higher than the frequency of hydrological droughts, and the frequency of extreme meteorological droughts events is significantly higher than that of hydrological droughts. In summer, rainfall is abundant, and reservoir storage will increase the occurrence of hydrological droughts. When droughts occur in other seasons, the release of water from the reservoir reduced the occurrence of hydrological drought and also reduced the occurrence of extreme drought events, which further proved that human activities that represented by reservoir water transfer and storage have obvious impacts on hydrological drought in the basin(Xiaoli Yang and Zhongwang Wei 2020). The meteorological drought duration and drought intensity of the basin are less than the hydrological drought duration except for Huangjiagang Station, indicating that the release of water from the reservoir in the dry season has a mitigation effect on the later hydrological drought events downstream. In general, the increasing trend of hydrological drought in the basin cannot be ignored, human activities represented by reservoirs have a significant impact on hydrological drought. On the one hand, water storage in the rainy season will increase the frequency of hydrological drought events resulted from increasing water, capturing; while the release of water during the dry season will reduce the occurrence of hydrological drought events. The effect of reducing the duration and intensity of hydrological drought events by releasing water from the reservoir is most obvious at Huangjiagang Station, which is the nearest to Danjiangkou Reservoir(Jiao et al. 2020).

Table 3 The comparison of drought characteristic on meteorological drought and hydrological drought events

\begin{tabular}{ccccc}
\hline Scale & Drought Tendency & Drought Frequency & Drought Duration & Drought Intensity \\
\hline Sping & $\mathrm{MD}<\mathrm{HD}$ & $\mathrm{MD}>\mathrm{HD}$ & $\mathrm{MD}<\mathrm{HD}^{*}$ & $\mathrm{MD}<\mathrm{HD}^{*}$ \\
Summer & $\mathrm{MD}<\mathrm{HD}$ & $\mathrm{MD}<\mathrm{HD}$ & $\mathrm{MD}<\mathrm{HD}^{*}$ & $\mathrm{MD}<\mathrm{HD}$ \\
Autumn & $\mathrm{MD}<\mathrm{HD}$ & $\mathrm{MD}>\mathrm{HD}$ & $\mathrm{MD}<\mathrm{HD}^{*}$ & $\mathrm{MD}<\mathrm{HD}$ \\
Winter & $\mathrm{MD}<\mathrm{HD}$ & $\mathrm{MD}>\mathrm{HD}$ & $\mathrm{MD}<\mathrm{HD}^{*}$ & $\mathrm{MD}<\mathrm{HD}$ \\
\hline
\end{tabular}

MD represents meteorological drought, HD means hydrological drought. * means that except for the conclusion of Huangjiagang Station, other areas in the basin conform to this conclusion.

\subsection{The Relationship between Hydrological Drought and Meteorological Drought}

\subsubsection{Correlation between Hydrological Drought and Meteorological Drought}

Meteorological drought mainly refers to the phenomenon of insufficient regional water caused by the imbalance of atmospheric precipitation and evaporation. It is sudden and can start or end quickly. 
Meteorological drought is directly affected by meteorological factors such as precipitation and evaporation, while hydrological drought is different that may be affected by hydrological features. When meteorological drought occurs, human demand for water to production and living causes continuous reduction of surface water and groundwater level, if this situation continues to a certain extent, hydrological drought formed(B et al. 2020). Therefore, the occurrence of hydrological drought is largely affected by meteorological drought, and the two have a certain correlation.

Fig .11(a) shows the correlation between the SRI series of the five control hydrological stations on the HRB mainstream at different time scales and the corresponding SPI series of the control basin at the same time scale at a significant level of $\alpha=0.01$. The correlation coefficient increases with the increase of the time scale, with the correlation coefficient of monthly scale is the smallest, and the correlation coefficient of the yearly scale is the largest. In the Spearman rank test method, under the significance level of $\alpha=0.01$, the value range of the test statistic $r$ is $[-1,1]$, when $r>0$ is positive correlation, and the closer its value is to 1 , the higher the correlation degree. Therefore, the correlation coefficients of all scales in the HRB have passed the significance test. The strongest correlation between meteorological drought and hydrological drought in the HRB is obviously on the yearly scale (SPI-12). Since the source data is the precipitation and flow data of the basin, and the two have their own certainties relevance from the perspective of the hydrological cycle process. Because the length of the annual-scale series is longer than that of the monthly-scale and seasonal-scale series. It not only has a larger amount of data, but also contains more changes in the meteorological and hydrological characteristics of the watershed. Therefore, to a certain extent, the correlation of precipitation and runoff in the source data of the series is better, so the SPI/SRI sequence calculated by it has the strongest correlation on the annual scale [14-16].

At the same time, the degree of correlation between hydrological drought and meteorological drought in the basin represented by different stations is varied. The hydrological drought and meteorological drought in Shiquan Station, Baihe Station, and Ankang Station in the upper reaches of the HRB are highly correlated, while the correlation between hydrological drought and meteorological drought of the Huangjiagang Station and Huangzhuang Station at middle and lower reaches of the HRB is relatively low, which is related to the violent human activities near the Danjiangkou Reservoir at the junction of the upper and middle and lower reaches of the HRB.

In order to further explore the impact of human activities on the drought situation in the HRB, combined with the mutation points of runoff, hydrological drought and related documents, 1990 was selected as the cut-off point, 1961-1990 as the base period, and 1991-2018 as the variation period, then calculate the correlation coefficients of SPI series and SRI series at various scales and different periods in the HRB (Fig .11b). The results show that the correlation between hydrological drought and meteorological drought in the base period at each scale at Huangjiagang Station and Huangzhuang Station located in the middle and lower reaches of the HRB is significantly less than that of the three stations on the upper reaches of the HRB. The correlation of meteorological drought was significantly reduced, while the other three stations did not change significantly. Hence, human activities represented by the retention and diversion of the Danjiangkou Reservoir have a significant impact on the hydrological drought in the middle and lower reaches of the HRB, and significantly reduce the correlation between hydrological drought and meteorological drought, at the same time, this influence becomes more and more obvious as the scale of research increases(Bae et al. 2019). 

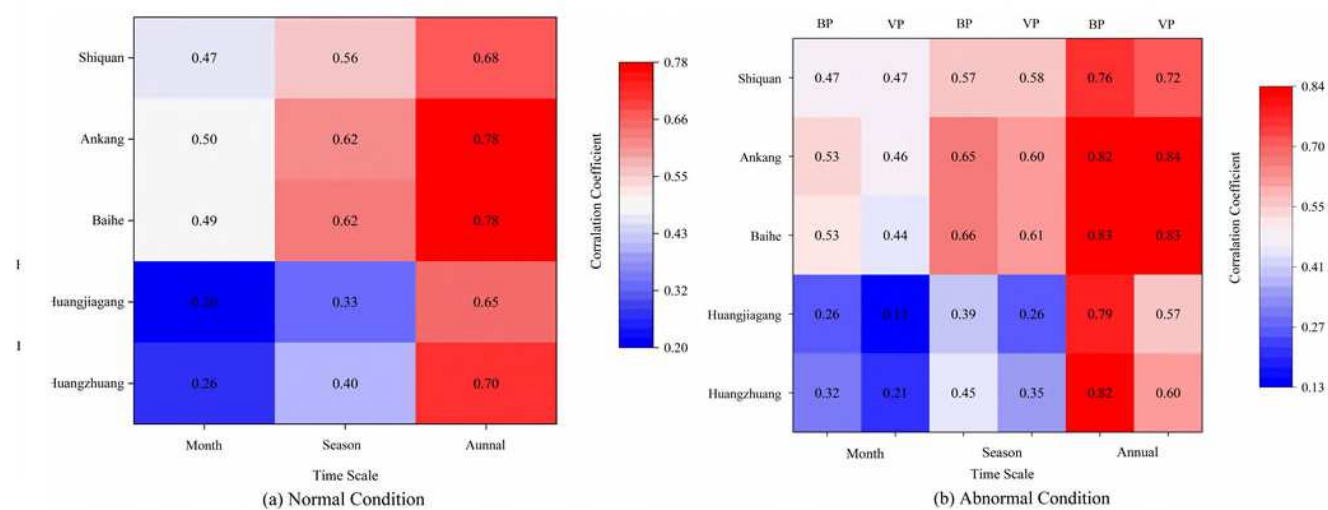

Fig .11 The correlation of meteorological drought and hydrological drought at five stations in HRB under normal and changing conditions on monthly, seasonal and yearly scale

\subsubsection{Hysteresis of Hydrological Drought to Meteorological Drought}

The cross-wavelet power spectrum can judge the relationship between two time series in the timefrequency domain and their significance based on the same energy spectrum area of different series. Therefore, the authors use this method to further analyze the correlation between meteorological drought and hydrological drought in the HRB. Similarly, taking Huangjiagang Station in the middle reaches of the HRB as a representative station, Fig .12 shows the cross-wavelet power spectrum of the SPI sequence and SRI sequence at the monthly, seasonal, and yearly scales at Huangjiagang Station. The Fig .12 shows that both SPI and SRI have a strong correlation at different scales. At the monthly scale, the SPI-1 sequence and the SRI-1 sequence have an obvious resonance period in the mid-frequency region, showing a positive correlation, especially in the period from 1970 to 1985 , there is an obvious 100-128 months positive correlation with the SRI sequence. While at the seasonal scale, the SPI-3 sequence and the SRI-3 sequence have an obvious resonance period in the low-frequency region, and there is a positive correlation between 10-32 months between 1990 and 2008, and it can be clearly seen that the arrow points downward, indicating the occurrence of meteorological drought earlier than the hydrological drought. At the yearly scale, the SPI-12 sequence and the SRI-12 sequence have a larger resonance period in the high-frequency region, showing a positive correlation from 1970 to 2010, and SRI still lags behind SPI.

In order to obtain a deeper conclusion, the authors compared the Spearman correlation coefficient $r$ value between SPI and SRI of various scales with significant resonance period during the whole study period (1961-2018). At the monthly scale, the $r$ values between the SPI and SRI sequences from 1961 to 2018 and the significant resonance period from 1970 to 1985 are 0.21 and 0.29 , respectively. While at the seasonal scale, the $r$ values for the two periods are 0.32 and 0.415 , respectively and the yearly scale, the $r$ values of the two periods are 0.648 and 0.724 . It is clear that the correlation coefficient between SPI and SRI is significantly improved during the significant resonance period based on the cross wavelet transform, which illustrates the importance of considering different time scales when studying the relationship between hydrological drought and meteorological drought. In general, there is a positive correlation between hydrological drought and meteorological drought at different time scales in the HRB, and hydrological drought is obviously lagging behind meteorological drought, but the synchronization of different scales is not consistent. The specific lag time will be discussed further. 

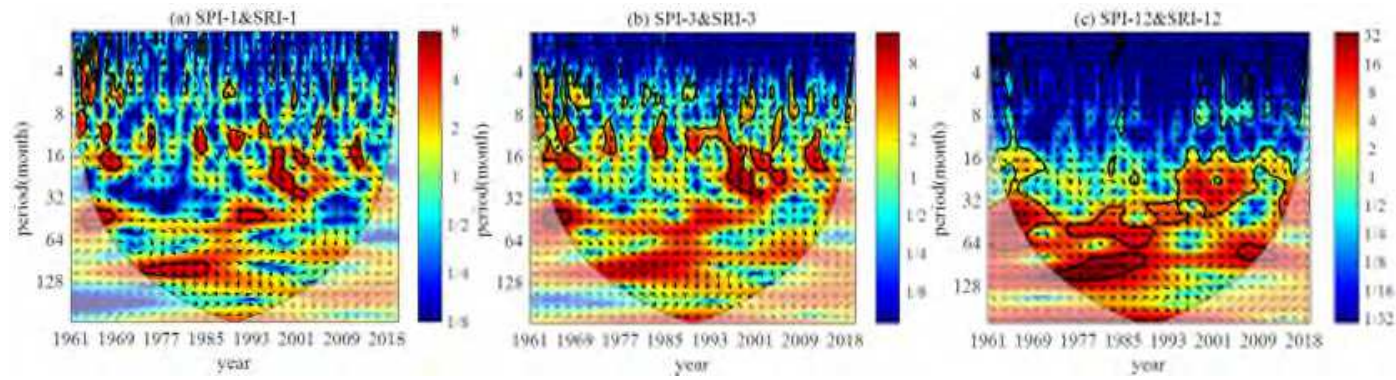

Fig. 12 The crossed wavelet power spectrum of monthly, seasonal and yearly SPI and SRI Sequences at Huangjiagang Station. The black solid line represents the wavelet influence cone, the color depth represents the strength of the correlation, the darker the color, the stronger the correlation, the black arrow forward represents advance, and backward represents lag.

The occurrence of hydrological drought lags behind meteorological drought, and the correlation between meteorological drought and hydrological drought on the yearly scale is the best. Therefore, the authors taking the yearly scale as an example, where they use the SPI-12 sequence of the same period, lag 1 month, lag 2 months...12 months as the time gradient, calculate the time lag correlation coefficient corresponding to different time gradients, and take the time gradient corresponding to the maximum value of the correlation coefficient as the lag time for SRI to SPI. Fig .13 show that there is a certain lag time between the hydrological drought and meteorological drought in the HRB on a yearly scale. The lag time between the hydrological drought of different hydrological stations and the meteorological drought of the control basin is different. The lag time in the upper HRB hydrological drought lags behind the meteorological drought is about 1 month, while the hydrological drought in the middle and lower reaches lags the meteorological drought by 2 months.

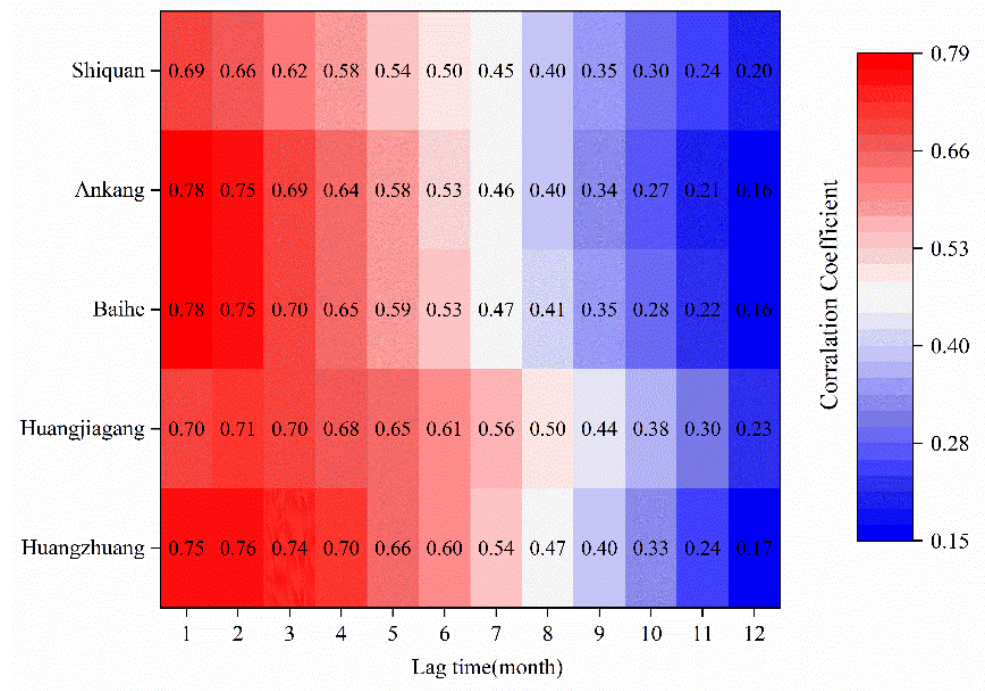

Fig. 13 The variation of lag time between meteorological and hydrological droughts on yearly scale in HRB. The month with the highest correlation coefficient represents the strongest correlation between hydrological drought and meteorological drought that lags behind this month, that is, the time that hydrological drought lags behind meteorological drought.

In order to explore the impact of human activities and climate change on the response of hydrological drought to meteorological drought in the middle and lower reaches of the HRB, similarly, the authors used 1990 as the differentiation point, 1961-1990 as the base period, and 1991-2018 as the variation period. The response changes of the HRB in different periods of hydrological drought and meteorological drought on different scales are showed (Fig .14). It shows that the lagging effects of human activities and climate change on the monthly hydro-meteorological drought are not obvious, and the lag time before 
and after the variation remains unchanged, while for the seasonal and yearly scales, it significantly reduced in the Huangjiagang station located in the middle and lower reaches of the HRB. The hydrological drought lag time at the Huangjiagang station and Huangzhuang station decreased from 2 months lag in the reference period to 1 month lag, which is inseparable from the human activities represented by the Danjiangkou Reservoir located upstream of the two stations. The primary indicator of the occurrence of meteorological drought is insufficient precipitation, which leads to a decrease in watershed runoff. However, the water intake, water use, and water transfer projects surrounding human activities in the basin continue to reduce water volume. The consequence of shortage is that the runoff of the watershed drops rapidly and the hydrological drought advances occurs, that is, the hydrological drought in the basin lags behind the meteorological drought significantly less(Al-Faraj and Scholz 2014; Leitman et al. 2016).
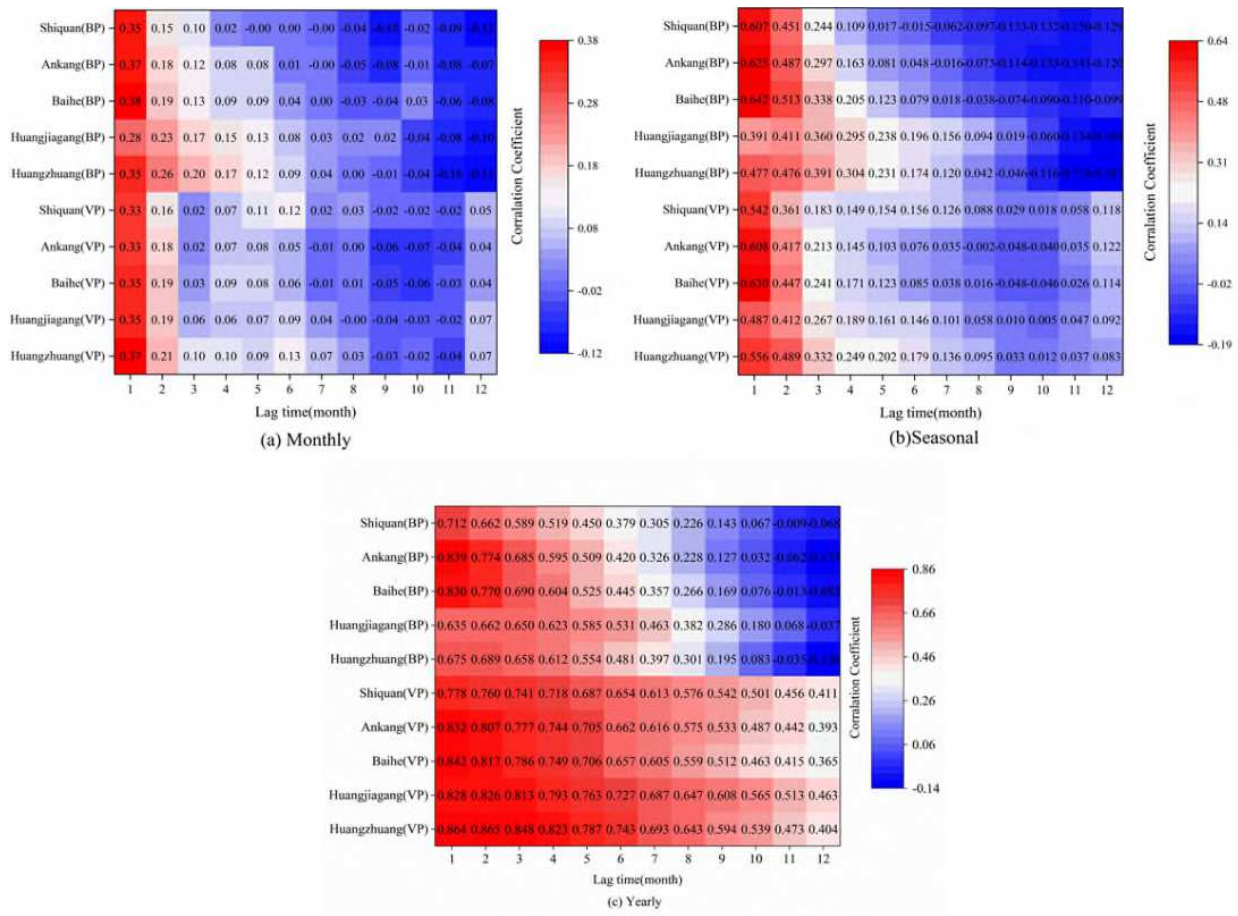

Fig. 14 The variation of lag time on multi-scale between meteorological and hydrological droughts in HRB, where the BP is the base period, VP is the variation period.

\section{Discussion and Conclusions}

In this study, meteorological and hydrological droughts analysis was carried out on the precipitation data and flow data of the Hanjiang River Basin from 1961 to 2018, and the correlation and responsiveness of meteorological and hydrological drought in the HRB at different temporal and spatial scales were studied, the following conclusions were obtained:

(1) The meteorological drought in the Hanjiang River Basin presents a complex cyclical trend of drought-flood-drought-flood with the main cycle of 2-4 years. The basin has entered a period of aggravation of drought since 1990 and a period of drought relief since 2010. It is of great importance to prevent the hazards of sudden drought caused by the complicated periodic changes of meteorological drought. On the spatial scale, the meteorological drought in the Hanjiang River Basin presents a clear trend of aridification in the central region and humidification in the southern and western regions. The aridification trend is the most obvious in the area around Danjiangkou Reservoir, and the four seasons of drought in the upper and middle reaches are also severe. The summer drought in the middle reaches and 
the winter drought in the lower reaches is more serious.

(2) The hydrological drought in the Hanjiang River Basin showed a significant and serious trend. The autumn drought was the most obvious, mainly in the Huangjiagang area; and followed by the spring drought, which was mainly observed manifested in Shiquan Station and Ankang Station, the summer drought was observed mainly manifested in Huangjiagang Station and Huangzhuang Station. In the area near Huangzhuang Station, the HRB in winter shows a trend of humidification as a whole, and the hydrological drought in the basin has an 8-year cycle. The hydrological drought frequency in the Hanjiang River Basin gradually decreases from upstream to downstream along the main stream. But the abnormal increase of hydrological drought frequency at Huangjiagang Station, $10 \mathrm{~km}$ downstream of Danjiangkou Reservoir, is closely related to human activities. Drought events in the river basin are mostly light and moderate drought events. The upper and middle reaches of the Hanjiang River Basin have high drought intensity, and the lower reaches have a longer drought duration. The drought at Huangzhuang Station lasted the longest.

(3) In the past ten years, the increasing trend of hydrological drought in the river basin cannot be ignored. Human activities represented by reservoirs have a significant impact on hydrological drought. Water storage during the rainy season will increase the frequency of hydrological drought events, while water release during the dry season will reduce hydrological drought events. The effect of reducing the duration and intensity of hydrological drought events by releasing water from the reservoir is most obvious at Huangjiagang Station, which is the nearest to Danjiangkou Reservoir.

(4) The Hanjiang River Basin has the best correlation between hydrological drought and meteorological drought on a yearly scale. After 1990, drastic human activities and climate change have reduced the correlation between hydrological drought and meteorological drought in the middle and lower reaches of the basin, and reduced the lag time of hydrological drought in the middle and lower reaches of the basin. The hydrological drought in the upper reaches of the basin lags behind the meteorological drought by 1 month, and the hydrological drought in the middle and lower reaches of the basin has changed from 2 months before 1990 to 1 month lagging in 1990.

Some scholars' studies have shown that the characteristics of drought changes in China have been unusually prominent under the climate background of increasing global temperature and increasing extreme precipitation in recent years(Han et al. 2019; Zhang et al. 2020). However, drought not only occurs in arid and semi-arid areas, but also occurs in humid and semi-humid areas, and it often causes more serious damage due to people's neglect(Huang et al. 2013). As the water source of the South-toNorth Water Diversion, the Hanjiang River is located in a humid-semi-humid area, so the occurrence of drought events has a great impact on the water supply security of the basin. Many scholars have also conducted research on the drought in the Hanjiang River Basin, the results show that the drought situation in the Hanjiang River Basin is present phase changes, and the occurrence of extreme events has increased, which is consistent with the conclusion of this paper(Chen et al. 2013; Xu et al. 2011). In the process of meteorological and hydrological drought in the study area, many studies have shown that there is a certain correlation between meteorological drought and hydrological drought, and climate change and human activities will affect this correlation(Li et al. 2019; Tijdeman et al. 2018). Wu et al and Zhang et al (Wu et al. 2016; Wu et al. 2018; Zhang et al. 2015)found that the operation of the reservoir will shorten the propagation time from meteorological drought to hydrological drought, and human activities have a more obvious impact on seasonal drought, and the impact of climate change on drought is dominant on a longer time scale. Wang et al. (Wang et al. 2020b)studied the influence of climatic factors on regional drought conditions, and the results showed that the degree of correlation between the drought index and climatic 
factors in the Qinghai-Tibet Plateau is affected by vegetation types, MA et al (Ma et al. 2018)showed that climate change in the Heihe River Basin tends to increase the propagation time of drought. Among the conclusions of this research, the meteorological and hydrological droughts in Hanjiang River Basin continued to be interrelated with hydrological drought lagging behind meteorological drought, the hydrological projects and reservoirs are playing role in alleviating or worsen the hydrological droughts during the rainy and dry season as result from store or release actions, and this is similar to the conclusions reached by other scholars.

The water resources of the Hanjiang River Basin basin have a significant influence on the water use area of Beijing-Tianjin-Hebei. So how to effectively monitor and predict drought conditions in the Hanjiang River Basin is of great significance. Javed er al. (Javed et al. 2020), Yuan et al.(Yuan et al. 2015) combined the NDVI and LST data of MODIS to study drought prediction in China and the Yangtze River Basin, it also provides a direction for our more in-depth research. At the same time, it is an important research direction to explore the impact of human activities and climate change on the transitivity of meteorological drought and hydrological drought in the Hanjiang River Basin and to quantify the impact of both in further research.

\section{Declarations}

Funding This research has been financially supported by the National Natural Science Foundation of China (grant nos. 41830863, 41330854, 51879162, 51609242, 51779146, 41601025), the National Key Research and Development Program of China (nos.2017YFA0605002. 2017YFA060500, 2017YFC040440, 2017YFC0404602), and the State Key Laboratory of Hydrology-Water Resources and Hydraulic Engineering (grant no. 2019nkzd02).

Conflicts of interest The authors declare no competing interests.

Availability of data and material The daily precipitation data is provided by the China National Meteorological Center, and the runoff data comes from the China Yangtze River Water Resources Commission and the processing codes supporting the results of this study, which should be obtained from the corresponding author in accordance with reasonable requirements.

Code availability The calculation code used in this article is written by the author or co-author.

Author Contributions All authors contributed to the study conception and design. The results analysis and drafting the manuscript were contributed by Wanglin. The manuscript and contributed results discussion was structured by Zhangjianyun and Amgad Elmahdi, Wanguoqin, Baozhenxin. The methodology of the work was perdormed by Shuzhangkang. The analysis on results reasonability was contributed by Pengtao and Linqingxia. The first draft of the manuscript was written by Wanglin, and all authors commented on previous versions of the manuscript. All authors read and approved the final manuscript.

Ethics approval Not applicable

Consent to participate Not applicable 


\section{References}

Al-Faraj FAM, Scholz M (2014) Assessment of temporal hydrologic anomalies coupled with drought impact for a transboundary river flow regime: The Diyala watershed case study Journal of Hydrology 517:64-73

Allen SK, Plattner GK, Nauels A, Xia Y, Stocker TF (2007) Climate Change 2013: The Physical Science Basis. An overview of the Working Group 1 contribution to the Fifth Assessment Report of the Intergovernmental Panel on Climate Change (IPCC).

B QLA, A PH, C YH, A XH, A TZ, D GL, E HW (2020) Investigation to the relation between meteorological drought and hydrological drought in the upper Shaying River Basin using wavelet analysis Atmospheric Research 234

Bae H, Ji H, Lim YJ, Ryu Y, Kim BJ (2019) Characteristics of drought propagation in South Korea: relationship between meteorological, agricultural, and hydrological droughts Natural Hazards 99:116

Caccamo G, Chisholm LA, Bradstock RA, Puotinen ML (2011) Assessing the sensitivity of MODIS to monitor drought in high biomass ecosystems Remote Sensing of Environment 115:2626-2639

Chen L, Singh VP, Guo S, Mishra AK, Guo J (2013) Drought Analysis Using Copulas Journal of Hydrologic Engineering 18:797-808

Chen X, Li F-w, Feng P (2018) Spatiotemporal variation of hydrological drought based on the Optimal Standardized Streamflow Index in Luanhe River basin, China Natural Hazards 91:155-178

Chiang F, AghaKouchak A, Mazdiyasni O (2018) Detection and attribution of shifts in drought frequency, duration, and intensity AGUFM 2018:GC11B-06

Dai A, Zhao T, Chen J (2018) Climate Change and Drought: a Precipitation and Evaporation Perspective Current Climate Change Reports 4:301-312 doi:10.1007/s40641-018-0101-6

Diaz V, Corzo Perez GA, Van Lanen HAJ, Solomatine D, Varouchakis EA (2020) An approach to characterise spatio-temporal drought dynamics Advances in Water Resources 137 doi:10.1016/j.advwatres.2020.103512

Fang Y, Qian H, Chen J, Xu H (2018) Characteristics of Spatial-Temporal Evolution of Meteorological Drought in the Ningxia Hui Autonomous Region of Northwest China Water 10 doi:10.3390/w10080992

Ge J (2019) Spatial-Temporal Variation Characteristics and Causes of Meteorological Drought in Shaanxi Province Northwest A\&F University

Gümüşsoy V (2017) Drought trends at Beyşehir Lake and its vicinity according to the Standardized Precipitation Index (SPI) EGU General Assembly Conference

Han L, Zhang Q, Jia J, Wang Y, Huang T (2019) Drought Severity, Frequency, Duration and Regional Differences in China Journal of Desert Research

Hao Z, Hao F, Singh VP, Xia Y, Ouyang W, Shen X (2016) A theoretical drought classification method for the multivariate drought index based on distribution properties of standardized drought indices Advances in water resources 92:240-247

Heim, Richard R (2002) A review of twentieth-century drought indices used in the United States Bulletin of the American Meteorological Society 83:1149-1165

Huang S, Li P, Huang Q, Leng G, Hou B, Ma L (2017) The propagation from meteorological to 
hydrological drought and its potential influence factors Journal of Hydrology 547:184-195 doi:10.1016/j.jhydrol.2017.01.041

Huang WH, Sui Y, Yang XG, Dai SW, Mao-Song LI (2013) [Characteristics and adaptation of seasonal drought in southern China under the background of climate change. V. Seasonal drought characteristics division and assessment in southern China] Ying Yong Sheng Tai Xue Bao 24:29172925

Javed T, Li Y, Yao N (2020) Drought evolution indicated by meteorological and remote-sensing drought indices under different land cover types in China Environmental Science and Pollution Research:117

Jiang S et al. (2019) A framework for quantifying the impacts of climate change and human activities on hydrological drought in a semiarid basin of Northern China Hydrological Processes 33:1075-1088 doi:10.1002/hyp.13386

Jiao D, Wang D, Lv H (2020) Effects of human activities on hydrological drought patterns in the Yangtze River Basin, China Natural Hazards

Kendall MG (1990) Rank Correlation Methods British Journal of Psychology 25:86-91

Khan M, Muhammad N, El-Shafie A (2018) A REVIEW OF FUNDAMENTAL DROUGHT CONCEPTS, IMPACTS AND ANALYSES OF INDICES IN ASIAN CONTINENT Journal of Urban and Environmental Engineering 12:106-119

Leitman S, Iii WEP, Kiker G (2016) Management Options During the 2011-2012 Drought on the Apalachicola River: A Systems Dynamic Model Evaluation Environmental Management 58:193207

Li J, Zhou S, Hu R (2015) Hydrological Drought Class Transition Using SPI and SRI Time Series by Loglinear Regression Water Resources Management 30:669-684 doi:10.1007/s11269-015-1184-7

Li Q, He P, He Y, Han X, Wang H (2019) Investigation to the relation between meteorological drought and hydrological drought in the upper Shaying River Basin using wavelet analysis Atmospheric Research 234:104743

Li Y, Wen Y, Lai H, Zhao Q (2020) Drought response analysis based on cross wavelet transform and mutual entropy Alexandria Engineering Journal 59:1223-1231 doi:10.1016/j.aej.2020.01.050

Lin H, Wang J, Li F, Xie Y, Jiang C, Sun L (2020) Drought Trends and the Extreme Drought Frequency and Characteristics under Climate Change Based on SPI and HI in the Upper and Middle Reaches of the Huai River Basin, China Water 12:1100

Lin Q, Wu Z, Singh VP, Sadeghi SHR, He H, Lu G (2017) Correlation between hydrological drought, climatic factors, reservoir operation, and vegetation cover in the Xijiang Basin, South China Journal of Hydrology 549:512-524 doi:10.1016/j.jhydrol.2017.04.020

Liu X, Luo Y, Yang T, Liang K, Zhang M, Liu C (2015) Investigation of the probability of concurrent drought events between the water source and destination regions of China's water diversion project Geophysical Research Letters 42:8424-8431 doi:10.1002/2015g1065904

Lorenzo-Lacruz J, Vicente-Serrano SM, González-Hidalgo JC, López-Moreno JI, Cortesi N (2013) Hydrological drought response to meteorological drought in the Iberian Peninsula Climate Research 58:117-131 doi:10.3354/cr01177

Ma F, Luo L, Ye A, Duan Q (2018) Drought Characteristics and Propagation in the Semiarid Heihe River Basin in Northwestern China Journal of Hydrometeorology 20

Mann HB (1945) Nonparametric test against trend Econometrica 13:245-259

McKee T B DNJ, Kleist J. (1993) The relationship of drought frequency and duration to time scales: 
Proceedings of Vulnerability Cambridge University Press

Mishra AK, Singh VP (2010) A review of drought concepts Journal of Hydrology 391:202-216 doi:10.1016/j.jhydrol.2010.07.012

Montaseri M, Amirataee B, Rezaie H (2018) New approach in bivariate drought duration and severity analysis Journal of Hydrology 559:166-181

Mu X, Zhao G, Hoermann G, Fohrer N, Xiong M, Su B, Li X (2012) Spatial patterns and temporal variability of dryness/wetness in the Yangtze River Basin, China Quaternary international

Mukherjee S, Mishra A, Trenberth KE (2018) Climate Change and Drought: a Perspective on Drought Indices Current Climate Change Reports

Niu J, Chen J (2016) A wavelet perspective on variabilities of hydrological processes in conjunction with geomorphic analysis over the Pearl River basin in South China Journal of Hydrology:392-409

Oloruntade AJ, Mohammad TA, Ghazali AH, Wayayok A (2017) Analysis of meteorological and hydrological droughts in the Niger-South Basin, Nigeria Global and Planetary Change 155:225-233

Qi Z, Qianyun C, Mengyan J, Pute W, Xuerui G, Meihong M, Yang H (2018) The Temporal-Spatial Characteristics of Drought in the Loess Plateau Using the Remote-Sensed TRMM Precipitation Data from 1998 to 2014 Remote Sensing 10:838-

Qin Z, Peng T, Singh VP, Chen M (2019) Spatio-temporal variations of precipitation extremes in Hanjiang River Basin, China, during 1960-2015 Theoretical and Applied Climatology 138:17671783 doi:10.1007/s00704-019-02932-7

Qing Y, Mingxing L, Ziyan Z, Zhuguo M (2017) Regional applicability of seven meteorological drought indices in China Science China Earth Sciences

Sattar MN, Lee J-Y, Shin J-Y, Kim T-W (2019) Probabilistic characteristics of drought propagation from meteorological to hydrological drought in South Korea Water Resources Management 33:24392452

Tijdeman E, Barker LJ, Svoboda MD, Stahl K (2018) Natural and Human Influences on the Link Between Meteorological and Hydrological Drought Indices for a Large Set of Catchments in the Contiguous United States Water Resources Research 54:6005-6023 doi:10.1029/2017wr022412

Wanders N, Wada Y (2015) Human and climate impacts on the 21st century hydrological drought Journal of Hydrology 526:208-220 doi:10.1016/j.jhydrol.2014.10.047

Wang F, Wang Z, Yang H, Di D, Zhao Y, Liang Q, Hussain Z (2020a) Comprehensive evaluation of hydrological drought and its relationships with meteorological drought in the Yellow River basin, China Journal of Hydrology 584 doi:10.1016/j.jhydrol.2020.124751

Wang R et al. (2019) Bivariate copula function-based spatial-temporal characteristics analysis of drought in Anhui Province, China Meteorology and Atmospheric Physics 131

Wang X, Zhang X, Wang J, Niu B (2020b) Variations in the Drought Severity Index in Response to Climate Change on the Tibetan Plateau Journal of Resources and Ecology 11:304

Wang X, Zhuo L, Li C, Engel BA, Sun S, Wang Y (2020c) Temporal and spatial evolution trends of drought in northern Shaanxi of China: 1960-2100 Theoretical and Applied Climatology 139:965979

Waseem M, Ajmal M, Kim T-W (2015) Development of a new composite drought index for multivariate drought assessment Journal of Hydrology 527:30-37 doi:10.1016/j.jhydrol.2015.04.044

Wu J, Chen X, Gao L, Yao H, Chen Y, Liu M (2016) Response of Hydrological Drought to Meteorological Drought under the Influence of Large Reservoir Advances in Meteorology 2016:111 
Wu J, Chen X, Yao H, Gao L, Chen Y, Liu M (2017) Non-linear relationship of hydrological drought responding to meteorological drought and impact of a large reservoir Journal of Hydrology 551:495507 doi:10.1016/j.jhydrol.2017.06.029

Wu J, Liu Z, Yao H, Chen X, Chen X, Zheng Y, He Y (2018) Impacts of reservoir operations on multiscale correlations between hydrological drought and meteorological drought Journal of Hydrology 563:726-736 doi:10.1016/j.jhydrol.2018.06.053

Wyckoff PH, Bowers R (2010) Response of the prairieâ“'forest border to climate change: impacts of increasing drought may be mitigated by increasing CO2 Journal of Ecology 98:197-208 doi:10.1111/j.1365-2745.2009.01602.x

Xiaoli Yang MZ, Xiaogang He, Liliang Ren1, Ming Pan , Xiaohan Yu,, Zhongwang Wei aJS (2020) Contrasting influences of human activities on hydrological drought regimes over China based on high - resolution simulations Water Resources Research 56

Xu Y, Zhang X, Wang X, Hao Z, Singh VP, Hao F (2019) Propagation from meteorological drought to hydrological drought under the impact of human activities: A case study in northern China Journal of Hydrology 579:124147

Xu YP, Lin SJ, Yan H, Zhang QQ, Ran QH (2011) Drought analysis using multi-scale standardized precipitation index in the Han River Basin, China Journal of Zhejiang University-SCIENCE A:483494

Yao N, Li Y, Lei T, Peng L (2018) Drought evolution, severity and trends in mainland China over 19612013 Science of the total environment 616:73-89

Yilmaz B (2019) Analysis of Hydrological Drought Trends in the Gap Region (Southeastern Turkey) by Mann-Kendall Test and Innovative Şen Method Applied Ecology and Environmental Research 17:3325-3342 doi:10.15666/aeer/1702_33253342

Yuan L et al. Drought monitoring and warning in the middle reach of Yangtze River with MODIS. In: IGARSS 2015 - 2015 IEEE International Geoscience and Remote Sensing Symposium, 2015.

Yuan X, Wood EF, Chaney NW, Sheffield J, Guan K (2016) Probabilistic Seasonal Forecasting of African Drought by Dynamical Models Journal of Hydrometeorology 14:1706-1720

Zhang D, Liu X, Bai P (2019) Assessment of hydrological drought and its recovery time for eight tributaries of the Yangtze River (China) based on downscaled GRACE data Journal of Hydrology 568:592-603 doi:10.1016/j.jhydrol.2018.11.030

Zhang Q, Xu CY, Zhang Z, Chen YD, Liu CL, Lin H (2008) Spatial and temporal variability of precipitation maxima during 1960-2005 in the Yangtze River basin and possible association with large-scale circulation Journal of Hydrology 353:215-227

Zhang Q, Yao Y, Li Y, Huang J, Zhang Y (2020) Causes and Changes of Drought in China: Research Progress and Prospects Journal of Meteorological Research 34:460-481

Zhang R, Chen X, Zhang Z, Shi P (2015) Evolution of hydrological drought under the regulation of two reservoirs in the headwater basin of the Huaihe River, China Stochastic Environmental Research \& Risk Assessment 29:487-499

Zhao R, Wang H, Zhan C, Hu S, Ma M, Dong Y (2020) Comparative analysis of probability distributions for the Standardized Precipitation Index and drought evolution in China during 1961-2015 Theoretical and Applied Climatology 139:1363-1377

Zhou Y, Guo S, Hong X, Chang F-J (2017) Systematic impact assessment on inter-basin water transfer projects of the Hanjiang River Basin in China Journal of Hydrology 553:584-595 

doi:10.1016/j.jhydrol.2017.08.039

847 